\title{
Solution Behavior of Modified Polyethylenimine [PEI] Polymers by Light Scattering Investigations
}

\author{
BY \\ Sonny A. EKHORUTOMWEN and Samuel P. SAWAN \\ Department of Chemistry, University of Massachusetts at Lowell \\ 1 University Avenue, Lowell, MA 01854 \\ Barbara F. SMITH, Thomas W. ROBISON and Kennard V. WILSON \\ Los Alamos National Laboratory \\ $127446^{\text {th }}$ Street, Los Alamos, NM 87594
}

\begin{abstract}
The eight average molecular weights, as well as other characteristics such as the second virial coefficients and root-mean-square (RMS) radii of gyration of poly [ethylene imine] (PEI) and various derivatives, have been determined in solution light scattering studies. The solution dynamics of PEI and carboxylated and phosphorylated derivatives were studied a pH of 3.3, 7.0 and 10.0. Measurements were made in freshly distilled and de-ionized water as well as in $0.1 \mathrm{M}, 1 \mathrm{M}$ and 5-M solutions of sodium chloride in water. Molecular weights were calculated from Berry plots. The purified polymer, PEI-1, gave a molecular weight of $39,600 \mathrm{~g} / \mathrm{mol}$, while the same polymer, which was not purified, PEI2 , has MW of $43,100 \mathrm{~g} / \mathrm{mol}$.

Increasing the concentration of sodium chloride leads to an increase in the root mean square radius of gyration, as the polymer chains become more extended and relaxed in a more concentrated salt medium. The apparent molecular weights are observed to decrease in proceeding from acidic to alkaline medium, especially with the phosphorylated polymer. However, the RMS radius of gyration of the carboxyl modified polymer was high at both ends of the $\mathrm{pH}$ scale, i.e., the polymer chains were extended at both the acidic and alkaline $\mathrm{pH}$ ends. The increase in RMS radius of gyration is indicative of increasing solvent-polymer interaction.
\end{abstract}




\section{INTRODUCTION}

Despite extensive studies in the last two decades, the dynamic light scattering behavior of flexible or branched polyelectrolytes in aqueous solutions is not yet fully understood $^{1}$. Most of the studies that have been carried out in the past couple of decades have been done on model polymers such as polystyrene $e^{2-4}$, polyethylene ${ }^{5-9}$, polyvinylacetate ${ }^{10-12}$ and polyisoprene ${ }^{13}$. Not much information had been available in the literature about the dilute solution properties of poly(ethylene imines) (PEI), branched or linear ${ }^{14,15}$, compared to the industrial polymers named above. Part of the reason for the lack of studies on PEI, has been due to its weak polyelectrolyte character ${ }^{16}$. Modified polyethylenmines are especially becoming popular with the hope that modifications will enhance the solution behavior of the polymers.

The selective removal and/or recovery of harzadous and valuable metal ions and radionuclides from various dilute aqueous streams are major concerns to the United States Government and environmentalists. Heavy metal contamination of the environment is caused by the wide usage of heavy metals in industries to meet the demand of modern society. However, polyethylenimine (PEI) a water-soluble polymer, has been found to have a great affinity to binding with metals, principally due to its polyelectrolyte character as well as their large macromolecular sizes which make them very useful in sequestering metal ions from dilute solutions. A recent paper by Park and $\mathrm{Choi}^{17}$, characterizes the solution properties of branched poly (ethylenimine).

Since its early development by Einstein ${ }^{18}$, Raman ${ }^{19}$, Debye ${ }^{20}$, Zimm $^{21},{ }^{22}$ and others ${ }^{23,24}$, the theory of light scattering from macromolecular solutions and suspensions has represented one of the major successes of chemical physics. Light scattering, indeed, is one of the few absolute methods available for the determination of molecular mass and structure, and certainly is applicable over the broadest range of molecular weights of any method. Until samples were able to be separated by high performance size exclusion chromatography (HPSEC), or gel permeation chromatography ${ }^{25}$, however, these measurements produced only weight average molecular weights, $\mathrm{Mw}$, and the corresponding $\mathrm{z}$-average square radii $\left(\mathrm{r}_{\mathrm{g}}{ }^{2}\right) \mathrm{z}$ together with the second virial coefficient, $A_{2}$. The use of HPSEC has resulted in the ability to analyze the distribution of broadly 
disperse samples as well as to obtain details of branching and molecular conformations. Thus, weight, number, and z-average values for both mass and size may be obtained for most samples by combining light scattering and HPSEC.

In this work, we present results of a study of the solution behavior of modified and PEI polymers in aqueous salt solutions. Light scattering measurements in solution of varying ionic strengths, $\mathrm{pH}$, electrolyte concentrations have been made to attempt to determine how the polymers exist in solution and the effects of added electrolyte.

\section{Basic Principles of Light Scattering}

1) The amount of light scattered is directly proportional to the product of molecular weight and solute concentration. ${ }^{26,27}$

2) The angular variation of scattered light is directly related to the size of the molecule ${ }^{28}$.

\section{Basic Theory and light scattering equations}

$$
\mathrm{K}^{*} \mathrm{C} / \mathrm{R}(\theta)=1 / \mathrm{MP}(\theta)+2 \mathrm{~A}_{2} \mathrm{C} \quad \text { eq. } 1
$$

Where

$K^{*}=4 \pi^{2}(\mathrm{dn} . / \mathrm{dc}) 2 \mathrm{n} 2 /\left(\mathrm{N}_{\mathrm{A}} \lambda^{4}\right)$, and $\mathrm{n}$ is the refractive index of the solvent.

C is the concentration of the solute molecules $(\mathrm{g} / \mathrm{ml})$.

$\mathbf{R}(\theta)$ is the fraction of light scattered relative to the incident beam.

$\mathbf{N}_{\mathrm{A}}$ is Avogadro's number.

$\lambda$ is the wavelength of light.

Dn./dc is the refractive index increment, which tells how much the refractive index of the solution varies with solute concentration.

$\mathbf{M}$ is the weight-average molecular weight of the solute.

$\mathbf{A}$ is the second virial coefficient (a measure of solvent-solute interaction).

$\mathbf{P}(\theta)$ is the "scattering function" which tells how the scattered light varies with angle. This variation is determined by $\left\langle\mathrm{r}^{2}\right\rangle$, the mean square radius (also known as radius of gyration). The bigger the radius of gyration the bigger the angular variation. 
$\left\langle\mathbf{r}^{2}\right\rangle$ is the mean square radius, describing the distribution of mass within the molecule, and it is given by the equation: ${ }^{29}$

$$
<\mathrm{r}^{2}>=\sum \mathrm{r}_{\mathrm{i}}^{2} \mathrm{~m}_{\mathrm{i}} / \mathrm{M}
$$

The symbol $R(\theta)$, the Rayleigh ratio describes the angle-dependent light scattering, and it is described as

$$
\mathrm{R}(\theta)=\mathrm{I}_{\theta} \mathrm{r}^{2} /\left(\mathrm{I}_{0} \mathrm{~V}\right)
$$

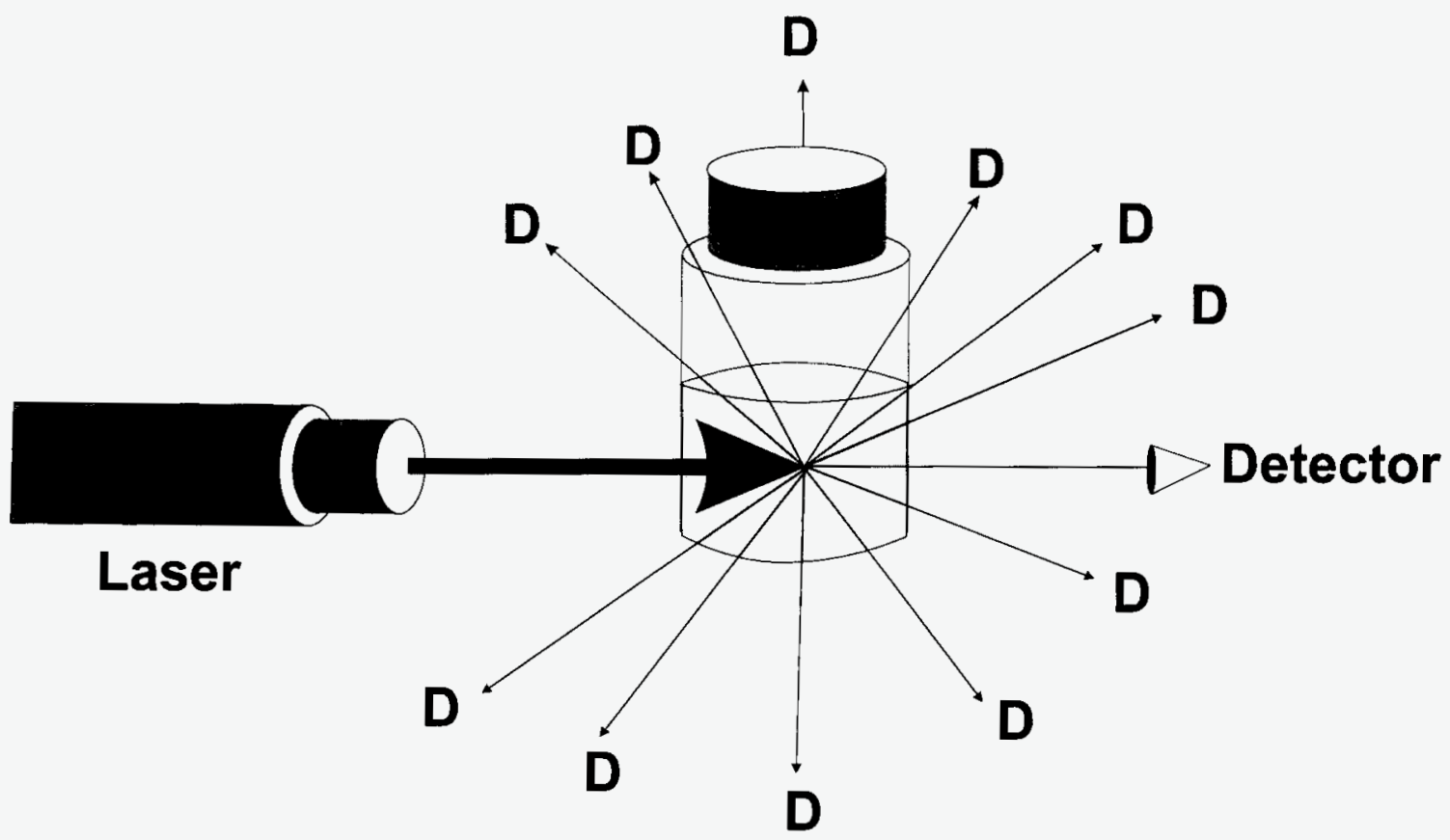

Figure 1. The light scattering pattern of particles in a solvent

$I_{\theta}$ is the scattered intensity, $I_{0}$ is the intensity of the incident beam, $V$ is the volume of the scattered medium, and $r$ is the distance between the scattering volume and the detector. Equation 3 implies that the dimensions of $R(\theta)$ are length $^{-1}$, and the DAWN instruments are provided with vertically polarized light sources. When studying a solution of solvent plus solute, it is convenient to use $\mathrm{R}(\theta)$ to represent the excess scattering of the solution compared to that of solvent alone as:

$$
R(\theta)=\left(I_{\theta}-I_{0, \text { solvent }}\right) r^{2} /\left(I_{0} V\right) \quad \text { eq. } 4
$$


where $\mathrm{I}_{0 \text {,solvent }}$ is the scattered intensity of the solvent. Equation 3 is used for pure solvent and equation 4 is used for a solution. That means that we are merely describing the scattering after subtracting the "baseline" of pure solvent. In this case, $R(\theta)$ is often called the excess Rayleigh ratio of the solute. The knowledge of Rayleigh ratio at a number of different angles leads directly to the weight-average molecular weight and mean square size of the solute molecules, making $R(\theta)$ the most important measured quantity in light scattering experiments.

The determination of molecular parameters of solute particles in solution is carried out by using the equation derived by Zimm, ${ }^{21}$ in which equation 1 is replaced by equation 5 .

$$
\mathrm{R}(\theta) / \mathrm{K}^{*} \mathrm{C}=\mathrm{Mw} \mathrm{P}(\theta)-2 \mathrm{~A}_{2} \mathrm{CM}_{\mathrm{w}}{ }^{2} \mathrm{P}^{2}(\theta) \quad \text { eq } 5
$$

Where $\mathrm{Mw}$ is the weight-average molecular weight, and other parameters defined previously. $P(\theta)$ is related to $<r^{2}>$ by the following equation:

$$
P(\theta)=1-2 \mu^{2}<r^{2}>/ 3+\ldots \quad \text { eq } 6
$$

where $\mu=(4 \pi / \lambda) \sin (\theta / 2)$, and gives us the relation between $P(\theta)$ and mean square radius for any molecules regardless of molecular conformation in the limit of $\mu^{2}<r^{2}>$ $<<1$. For a polydisperse sample, the mean square radius obtained is $\mathrm{z}$-average, usually written $<\mathrm{r} 2>\mathrm{z}$.

The determination of molecular weights and mean square radii are through the use of Zimm, Debye or Berry plot ${ }^{30}$. The Zimm and Debye plots are similar. To construct a Debbie plot, $\mathrm{Y}$ axis- $=\mathrm{R}(\theta) / \mathrm{K}^{*} \mathrm{C}$ and $\mathrm{X}$-axis $=\operatorname{Sin}^{2}(\theta / 2)+\mathrm{KC}$ where $\mathrm{K}$ is a "stretch factor" which scales the contributions from $\mathrm{c}$ to be roughly equal to the contributions from $\sin ^{2}(\theta / 2)$. It is chosen to be the reciprocal of the maximum concentration. In the case of the Zimm plot, we plot $Y=K^{*} C / R(\theta)$ and $X$-axis $=\operatorname{Sin}^{2}(\theta / 2)+K C$. The $y$-axis is the reciprocal of that used for Debye plot.

\section{EXPRIMENTAL}

Freshly made distilled and de-ionized water was used in this investigation. The $\mathrm{pH}$ values of the water were taken immediately and after 3 days, with Orion Research $\mathrm{pH}$ 
meter. The $\mathrm{Ph}$ values of 3 different concentrations of Nalco solutions as buffer systems were also measured. These were $0.1 \mathrm{M} \mathrm{Nalco}, 1 \mathrm{M} \mathrm{NaCl}$, and $5 \mathrm{M} \mathrm{NaCl}$ solutions respectively. The molecular weights (MW) of PEI were determined in water as well as 3 $\mathrm{NaCl}$ solutions. The distilled and deionized water was initially filtered with $2-\mu \mathrm{m}$ membrane filters, to make the $\mathrm{NaCl}$ solutions. Then the $\mathrm{p} \mathrm{H}$ Values of the solutions were measured

\subsection{Molecular weight measurement by light scattering method}

2.1.1 Measurement of $\mathbf{d n} . / \mathbf{d c}$ : This was done with Wyatt Technology Optilab Differential refractometer 903 using a series of solutions of the polymer with different concentrations. This is a measurement of differential refractive index changes with concentrations.

2.1.2 The light scattering measurements: were done on DAWN F Laser photometer (Wyatt Technology, Inc., CA), using a series of concentrations of the polymer solution. The final polymer solutions were filtered again with $0.2-\mu \mathrm{m}$ membrane filters to avoid light scattering from extraneous dust and other particles. The MW was calculated from Berry plots.

2.1.3 Polyethylenimine was obtained from BASF. The polymers consisted of purified PEI, unpurified PEI, with about 50\% water, some functionalized PEI, e g., carboxylated and phosphorylated polyethylenimines.

\section{RESULTS AND DISCUSSION}

\subsection{Native, unfunctionalized polyethylenimine (PEI).}

The effect of $\mathrm{pH}$ on polyelectrolytes in aqueous solutions is extremely important in the determination of their molecular dimensions. In this report, the $\mathrm{pH}$ of all the solutions including distilled water and the aqueous solutions were strictly controlled. The standard $\mathrm{pH}$ values of the starting solutions are shown in Table 1. The Molecular Weight characteristics for two batches of samples are provided in Tables 2 and 3. Tables 2 and 3 contain measured quantities such as RMS radius of gyration, $\left\langle\mathrm{r}^{2}\right\rangle$, second virial coefficient, $A_{2}$, and weight-average molecular weight, $M_{w}$. The RMS radius of gyration 
describes the distribution of mass within the molecule. This defines the radius of the volume within which a single polymer molecule gyrates ${ }^{32}$. The Second virial coefficient derives from osmotic pressure. The free energy of mixing of a polymer solution with normal heat of mixing is given as:

$$
<\mathrm{G}=\mathrm{KT}\left[\mathrm{N}_{1} \ln \mathrm{V}_{1}+\mathrm{N}_{2} \ln \mathrm{V}_{2}+\chi_{1} \mathrm{~N}_{1} \mathrm{~V}_{2}\right] \quad \text { eq } 7
$$

The partial molar free energy of mixing is given as:

$$
<\mathrm{G}_{1}=\mathrm{KT}\left[\ln \left(1-\mathrm{V}_{2}\right)+(1-1 / \mathrm{X}) \mathrm{V}_{2}+\chi_{1} \mathrm{~V}_{2}{ }^{2}\right] \quad \text { eq } 8
$$

from which osmotic pressure, $\pi$ is derived as:

$$
\pi=\mathrm{KT} / \mathrm{V}_{1}\left[\ln \left(1-\mathrm{V}_{2}\right)+(1-1 / \mathrm{X}) \mathrm{V}_{2}+\chi_{1} \mathrm{~V}_{2}^{2}\right] \quad \text { eq } 9
$$

and finally gives rise to osmotic pressure as:

$$
\pi=\mathrm{KT} / \mathrm{V}_{1}\left[\mathrm{~V}_{2} / \mathrm{X}+\left(1 / 2-\chi_{1}\right) \mathrm{V}_{2}{ }^{2}+\ldots \ldots . .\right] \quad \text { eq } 10
$$

where $V_{1}=$ the molecular volume of the solvent and the coefficient of $V_{2}{ }^{2}$ is known as the second virial coefficient, $\mathrm{A}_{2}$, which is given as:

$$
A_{2}=V_{2}^{2} / N_{O} V_{1}\left(1 / 2-\chi_{1}\right)
$$

where $V_{2}$ is the specific volume of the polymer and $A_{2}$ is directly proportional to $V_{2}^{2}$. $\mathrm{MW}$ is molecular weight and $\mathrm{M}_{\mathrm{w}}$ is the weight-average molecular of the polymers.

These materials were dissolved in $1 \mathrm{M} \mathrm{NaCl}$ solution, and adjusted to $\mathrm{pH}$ 7.0. PEI-1 has a weight-average molecular weight of $39,600 \mathrm{~g} / \mathrm{mol}$ while PEI-2 has a weightaverage molecular weight of $43,100 \mathrm{~g} / \mathrm{mol}$. This should be expected, because a purified 
material (almost always slightly fractionated) has a higher molecular weight than the unpurified one. PEI-1 was received, as a purified polymer while PEI-2 was unpurified, as received from BASF. The process of purification, as in fractional precipitation, separates the useful high molecular weight fractions from the low molecular weight fractions,

which are usually washed out ${ }^{31}$. This explains the sharp difference in the molecular weights of PEI-1 and PEI-2.

\subsection{Functionalized PEI}

Table 2 also shows the molecular weight values for the other materials, including those that were functionalized. PEI-6, PEI-8 and PEI-11 show high molecular weights. This might be due to the functionalization and eventual purification of the materials. Some of them have very large crystal sizes, e.g. PEI-8. The large molecular dimensions measured for some of the functionalized polymers could be due to the increased polyelectrolyte character due to derivatization and the increased tendency of larger macromolecular aggregations resulting from polar (ionic) attractions.

\subsection{Effects of Salt Concentration, $\mathrm{pH}$ and Polymer concentration on the molecular weight of Phosphorylated PEI (PEIP)}

Figure 3 summarizes the effects of \% functionalization on the MW weight and second virial coefficient of PEIP. As the \% functionalization increases from $25 \%$ to $100 \%$, the molecular weight decreases, as polar and ionic interactions become stronger. At the same time, the second virial coefficient increases as the solvent $(1 \mathrm{M} \mathrm{NaCl}$ solution) become a better solvent.

Figures 4 and 5 show the effects of $\mathrm{pH}$ on the polymer molecular dimensions. The molecular size at the $\mathrm{pH}$ examined; $2.5,3.3,7.15$ and 10.12 , shows that the molecular weight is the highest at the neutral $\mathrm{pH}$ range of about 7.15. At both ends of the $\mathrm{pH}$ scale, the molecular weights are much smaller. The acid and alkaline ranges exhibit strong polar and ionic interactions that effectively coil the polymer molecules. This trend is also true for the second virial coefficients and the root mean squared radius of gyration. 
To effectively determine the dimensions of polymer chains, it is very important that no aggregations are formed in solution. To this end, a small quantity of $\mathrm{NaCl}$ dissolved in distilled and deionized water to prevent polymer aggregations. The salt concentrations used were $0.1 \mathrm{M}, 1 \mathrm{M}, 3 \mathrm{M}$ and $5 \mathrm{M} \mathrm{NaCl}$ solutions, with the $\mathrm{pH}$ adjusted to 7.0. The effects of salt concentrations are shown in Figures 6 and 7. At low salt (0.1 M) $\mathrm{NaCl}$ concentration, both molecular weight and root mean radius of gyration were found to be very high, as the low salt concentration was not sufficient in buffering the polymer molecules. Increasing the salt concentration to $1 \mathrm{M}$ leads to drastic reduction of both RMS radius and MW, and increasing the Salt concentration further stabilizes both of these values as shown in Figure 6. Figure 7 specifically describes the effect of salt concentration on the second virial coefficient, $\mathrm{A}_{2}$, which decreases as ionic concentration increases to I $M$, but increases and stabilizes as the ionic concentration increases. Higher salt concentration makes a better solvent.

The effects of polymer concentration on MW of PEIP0.5 are shown in Table 8 \& 9 and in Figure $8 \&$ 9. At low polymer concentration, the molecular chains are more relaxed and stretched out, leading to a rather high RMS radius of gyration. As the polymer concentration increases the RMS radius of gyration decreases and eventually reaches equilibrium, as the polymer chains have no more space to extend.

\subsection{Effects of salt concentration, $\mathrm{pH}$ and polymer concentration, on the molecular weight characteristics of PEIC, Carboxyl modified PEI.}

The effect of $\mathrm{pH}$ on the carboxyl modified PEI, seems to be dependent on whether medium is acid or alkaline. Both molecular weight and the root mean square radius of gyration are relaxed at the acid $\mathrm{pH}$ region as seen in Figure 10 and Figure 11. PEI is more or neutral to acid or base, but when functionalized by carboxylation, the polymer chains become more acidic than basic. As the $\mathrm{pH}$ of the medium progressively becomes alkaline, both the molecular weight and root mean square radius of gyration decrease because the strong acid environment is progressively neutralized. It seems that the controlling factor here is the imbalance of ionic forces at both ends of the $\mathrm{pH}$ scale that 
leads to repulsion and extension of the molecules or vice versa. The behavior of the second virial coefficient is similar to those of $\mathrm{MW}$ and $\mathrm{A}_{2}$.

The effects of salt concentration on PEIC can be seen in Figures 12 and 13. At low ionic concentration, e.g., $0.1 \mathrm{M} \mathrm{NaCl}$, both molecular weight and root mean square radius of gyration have small values. But at $1 \mathrm{M}$ salt concentration, MW and RMS have their highest values. At both acid and alkaline regions, polar and ionic interactions are strongest. This leads to smaller molecular dimensions at these regions.

Polymer concentration has significant effect on the molecular weight of PEIC AS shown in Figures 14 and 15. At low polymer concentrations, the molecular weight and root mean radius of gyration, have low values. As the concentration increases, MW and RMS increase. At a polymer concentration of $4.00 \times 10^{-3} \mathrm{~g} / \mathrm{ml}$, MW and RMS increase rapidly. These rapid increases in these molecular dimensions are due to aggregations of polymer chains, above the critical concentration of $4.00 \times 10-3 \mathrm{~g} / \mathrm{ml}$. (Molecular Diagram 1). It is however better to run the experiments at lower polymer concentrations for very high molecular weight polymers, to avoid saturation of the detectors, due to excessive scattering of light rays from large particles, which eventually leads to faulty results.

There are some limitation to the tandem technique of light scattering and HPSEC. Theoretically, light scattering measurements may resolve size down to about a twentieth of the incident wavelength. For a given concentration $c(\mathrm{~g} / \mathrm{ml})$, the scattered light signal is proportional to $c M w$. Thus, for molecular weights below a few thousand, relatively high concentrations may be required so that the molecules can produce a detectable LS signal. Furthermore, the technique requires a parallel or serial determination of mass concentration for each eluting fraction. At high molecular weights and very low concentration, conventional mass concentration detectors (based on measurement of refractive index change) have difficulty determining concentration values accurately. Finally, an accurate determination of the refractive index increment with molecular concentration, $d n . / d c$ is required. For heterogeneous copolymers, $d n . / d c$ must be measured at each elution, since it may be a function of molecular size. In our systems, we considered the polymers as predominantly homogeneous, and therefore a single value for 
$d n . / d c$ was used. For polyelectrolytes, a more tedious dialysis step is rigorously required. This was overlooked in our procedure.

Nevertheless, even with these problems, light scattering certainly represents the most accurate and powerful molecular weight measurement and detection technique. Light scattering is absolute and does not require calibration of the columns.



\section{Molecular Diagram 1}

\subsection{Critical Micelle Concentrations [CMC], and aggregations.}

Some polymers form different agglomerations or aggregations in solution due to polar or ionic interactions or hydrogen bond formations. In either case it is extremely difficult to determine the exact molecular weights of the individual molecules. The critical micelle concentration (CMC) is the concentration above which polymer molecules aggregate together due to polar or other interactions. Due to the large molecular weight values measured for some of the polymers, we thought it extremely important to ascertain if the polymer molecules aggregated at certain concentrations for PEIC 0.5 and PEIP 0.5. We therefore measured the molecular weights for industrial use concentration $(0.416$ to $0.020 \mathrm{Wt} \%)$ and at low concentration $(0.0106$ to $0.000707 \mathrm{Wt}$ $\%$ ). For both polymers there seems to be no significant differences between the molecular weights calculated from low concentrations and those calculated from industrially used concentrations.

\section{CONCLUSIONS}


The absolute molecular weights (MW) of purified and unpurified polyethylenimines PEI as well as carboxylated and phosphorus modified version have been determined by light scattering method. Generally, it was observed that the MW of the phosphorus modified PEI, as well as the second virial coefficient and root mean square radius of gyration decrease as a function of increasing polymer concentration initially, then stabilize above a concentration of $4.00 \times 10^{-3} \mathrm{~g} / \mathrm{ml}$. For PEIP polymer, the polymer concentration range should be between $4.00 \times 10^{-3}$ to $1.00 \times 10^{-2} \mathrm{~g} / \mathrm{ml}$. For PEIP polymers, there are strong ionic and polar interaction at both ends of the $\mathrm{pH}$ scale, whereas for PEIC, opposite charges attract more strongly as $\mathrm{pH}$ increases into the alkaline range leading to the decrease in MW, RMS radius of gyration and second virial coefficient.

Light scattering has been confirmed as the method of choice for mass and size characterization by virtue of new instrumentation and new techniques. On one hand, light scattering photometers have now been developed that can measure the angular variation of the scattered light intensity at 15 to 18 distinct scattering angles simultaneously and repeatedly. For smaller molecules, a 3-detector system will suffice. This has ensured a high degree of precision in the deduction of key molecular parameters from the measured scattered light intensities. New and improved electronics have increased sensitivity significantly while decreasing detector drift and other temperature dependent effects.

\section{REFERENCE}

1. Roy G. Smiths; Maxim E. Kuil; Michael Mandel, Macromolecules, 27, 55995608

(1994).

2. Roovers, J. E. L., Bywater, S., Macromolecules, 9, 873 (1976).

3. Roovers, J. E. L., Polymer, 20, 843 (1979).

4. Masuda, T., Ohta, Y., Onogi, S., Macromolecules, 19, 2524 (1986).

5. Taromi, F. A., Grubisic-Gallot, Z., Rempp, P., Eur. Polym. J. 25, 1183, (1989).

6. Axelson, D. E., Knapp, W. C., J. Appl. Polym. Sci., 25, 119 (1980).

7. Lecacheux, D., Lesec, J., Quivoron, C., J. Appl. Polym. Sci., 27, 4867 (1982). 
8. Chu, B., Onclin, M., Ford, J. R., J. Phys. Chem., 88, 6566 (1984).

9. Bugudu, D. C., Rudin, A., J. Appl. Polym. Sci.; 33, 87 (1987).

10. Pang, S., Rudin, A., Am. Chem. Soc., Polym. Mater. Sci. Eng.65, 95 (1991).

11. Park, W. C., Graessley, W. W., J. Polym. Sci. Polym. Phys. Edn. 15, 71 (1977).

12. Wang, Q. W., PARK, I. H.Chu, B, Am. Chem. Soc. Symp. Ser., 352, 240 (1987).

13. Bauer, B. J., Fretters, L. J., Graessley, W. W., Hadjichristidis, N., Quack, G. F., Macromolecules, 22, 2337 (1989).

14. Van Den Berg, J. W. A., Bloys Van Treslong, C. J., Polderman, A., Rec. Trav. Chim., 92, 3 (1973).

15. Dick, R. C., Ham, G. E., J. Macromol. Sci. Chem. A, 4, 1301 (1970).

16. Mark, H. F. et al., (Eds.) "Encyclopedia of Polymer Science and Technology" $2^{\text {nd }}$ Edition, vol. 1, John Wiley, New York, pp 680-723 (1985)

17. Hyun Park and E-Joon Choi, Polymer, Vol. 37 (2), pp 313-319, (1996).

18. Einstein, A., Ann. Phys., 33, 1275 (1910).

19. Raman, C. V., Indian J. Phys., 2, 1 (1927).

20. Debye, P., J. Appl. Phys. 15, 338 (1944).

21. Zimm, B. H., J. Chem. Phys. 16, 1093-1099 (1948).

22. Zimm, B. H., J. Chem. Phys., 13, 141 (1945).

23. Zimm, B. H., Stein, R. S., Doty, P., Polymer Bull., 1, 90 (1945).

24. Fixman, M., J. Chem. Phys., 23, 2074 (1955).

25. Moore, J. C., J. Polym. Sci., A2, 835 (1964).

26. Kamide, K; Saito, M; Miyazaki, Y; "Molecular weight determination", in Polymer

Characterization, Blackie Academic and Professional Press, London, Ch. 5, (1993).

27. Kent, M. S.; Tirrell, M.; "Solution properties of polymer mixtures”, Macromolecules, 25, 5383 (1992).

28. Kamide, K.; Saito, M.; Miyazaki, Y.; "Molecular weight distribution”, Polymer characterization, 115-144 (1993).

29. Wyatt, P. J.; "Light scattering and the absolute characterization of 
macromolecules", Analytica Chimica Acta, 272, 1-40 (1993).

30. Salamone, J. C., Thompson, A. M., Su, C. H., Watterson, A. C.; “An investigation of the molecular dimensions of an ampholytic/amphiphilic ionomer in solution via light scattering," Polymer Preprints, 30, 326 (1989).

31. Ehorutomwen, S. A.; "Polysilanes: synthesis, modifications, electronic and photochemical properties." A Ph.D. thesis submitted to the University of Massachusetts at Lowell, Lowell, MA, 176p September (1995).

32. F. W. Billmeyer, Jr., "A textbook of Polymer Science", $3^{\text {rd }}$ Edition, John Wiley and Sons, chapter 8, pp 186-228 (1984).

33. Mueller, G.; Lane, J. P.; Fenyo, J. C.; J. Polym. Sci., Chem., 17, 659 (1979).

Table 1

\begin{tabular}{|c|c|c|}
\hline Serial \# & Solution & $\mathbf{p H}$ at $\mathbf{2 3}{ }^{\circ} \mathbf{C}$ \\
\hline 1 & Fresh distilled water & 7.79 \\
\hline 2 & Distilled water after 3 days & 7.78 \\
\hline 3 & $0.1 \mathrm{M} \mathrm{NaCl}$ & 6.82 \\
\hline 4 & $1 \mathrm{M} \mathrm{NaCl}$ & 6.17 \\
\hline 5 & $5 \mathrm{M} \mathrm{NaCl}$ & 5.61 \\
\hline
\end{tabular}






$\mathrm{DN} / \mathrm{DC}=0.174$, for Polyethylene imine (PEI).

Figure 2. A representative Berry plot used to calculate the molecular weight, second virial coefficient and the root mean square radius of gyration of PEI

$\underline{\text { Table } 2}$

\begin{tabular}{|c|c|c|c|c|}
\hline ID $\#$ & Remark & RMS (nm) & $\mathbf{A 2}(\mathbf{m o l ~ m l / g )}$ & $\mathbf{M W}(\mathbf{g} / \mathbf{m o l})$ \\
\hline PEI-1 & PEI Purified & $39.8+/-6.7$ & $1.30+/-1.0 \mathrm{e}-04$ & $3.96+/-0.1 \mathrm{e}+04$ \\
\hline PEI-2 & PEI Unpurified & $38.8+/-6.9$ & $5.71+/-2.0 \mathrm{e}-05$ & $4.31+/-0.2 \mathrm{e}+04$ \\
\hline PEI-3 & $\begin{array}{c}\text { Unpurified } \\
\text { (Polymin P) }\end{array}$ & $42.3+/-6.0$ & $5.09+/-0.4 \mathrm{e}-04$ & $5.19+/-0.2 \mathrm{e}+04$ \\
\hline PEI-4 & PEIP 0.5 & $39.3+/-4.3$ & $4.96+/-0.7 \mathrm{e}-04$ & $3.16+/-0.1 \mathrm{e}+04$ \\
\hline
\end{tabular}




\begin{tabular}{|c|c|c|c|c|}
\hline PEI-5 & PEIC 0.5 & $47.1+/-7.0$ & $7.49+/-3.0 \mathrm{e}-04$ & $1.60+/-0.07 \mathrm{e}+04$ \\
\hline PEI-6 & PEIP & $45.6+/-5.6$ & $3.88+/-0.2 \mathrm{e}-04$ & $4.12+/-0.4 \mathrm{e}+05$ \\
\hline PEI-7 & PEIP & $40.2+/-5.3$ & $6.77+/-0.5 \mathrm{e}-03$ & $5.97+/-0.3 \mathrm{e}+03$ \\
\hline PEI-8 & PEIC 0.5 & $49.6+/-6.5$ & $5.40+/-0.7 \mathrm{e}-04$ & $5.69+/-0.3 \mathrm{e}+04$ \\
\hline PEI-9 & PEIP & $46.1+/-5.6$ & $6.61+/-7.0 \mathrm{e}-04$ & $9.61+/-0.7 \mathrm{e}+03$ \\
\hline PEI-10 & PEIP & $44.5+/-6.9$ & $1.89+/-0.4 \mathrm{e}-03$ & $1.89+/-0.1 \mathrm{e}+04$ \\
\hline PEI-11 & PEIP 0.5 & $39.8+/-5.7$ & $1.41+/-0.2 \mathrm{e}-04$ & $1.12+/-0.04 \mathrm{e}+05$ \\
\hline PEI-12 & PEIP 0.5 & $38.1+/-4.9$ & $1.09+/-0.4 \mathrm{e}-03$ & $1.29+/-0.06 \mathrm{e}+04$ \\
\hline
\end{tabular}

Table 3

\begin{tabular}{|c|c|c|c|}
\hline SERIAL \# & RMS $(\mathrm{nm})$ & A2 $(\mathrm{mol} \mathrm{ml} / \mathrm{g})$ & MW $(\mathrm{g} / \mathrm{mol})$ \\
\hline PEIC0.25 (1) & $38.4+/-5.4$ & $6.18+/-2.0 \mathrm{e}-05$ & $5.86+/-0.3 \mathrm{e}+04$ \\
\hline PEIC0.5(2) & $37.6+/-6.6$ & $3.40+/-1.0 \mathrm{e}-04$ & $1.11+/-0.05 \mathrm{e}+04$ \\
\hline PEIC0.5(3) & $40.5+/-6.7$ & $7.68+/-0.5 \mathrm{e}-05$ & $1.18+/-0.05 \mathrm{e}+05$ \\
\hline PEIC0.5(4) & $36.6+/-4.9$ & $4.22+/-0.8 \mathrm{e}-04$ & $7.26+/-0.3 \mathrm{e}+04$ \\
\hline PEIC0.5(5) & $36.4+/-7.0$ & $2.87+/-0.6 \mathrm{e}-05$ & $3.43+/-0.2 \mathrm{e}+04$ \\
\hline PEIC0.75(6) & $37.8+/-5.6$ & $6.52+/-0.9 \mathrm{e}-05$ & $6.14+/-0.4 \mathrm{e}+04$ \\
\hline PEIC1.0(7) & $34.5+/-6.0$ & $3.43+/-0.4 \mathrm{e}-04$ & $4.76+/-0.3 \mathrm{e}+04$ \\
\hline PEIC1.0(8) & $36.8+/-5.0$ & $2.64+/-0.05 \mathrm{e}-04$ & $3.62+/-0.1 \mathrm{e}+04$ \\
\hline
\end{tabular}


Effects of \% Functionalization on $\mathrm{MW}$ and $\mathrm{A}_{2}$ OF PEIP ( $\mathrm{pH} 7.0 /$ salt conc. I M NaCl/polymer stock conc. $4.83 \mathrm{e}-3$, at $25^{\circ} \mathrm{C}$ )

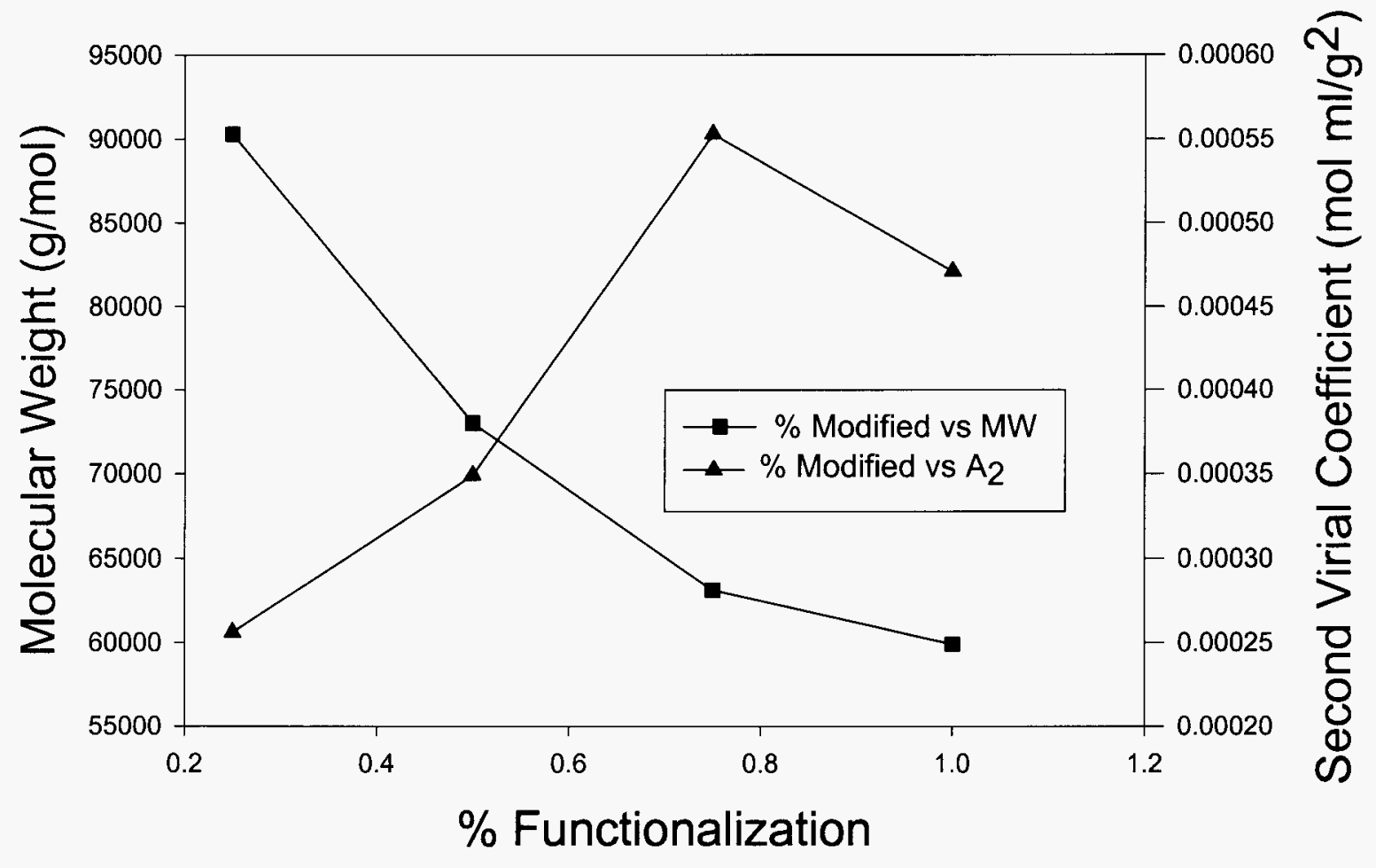

Figure 3 


\section{Effects of $\mathrm{pH}$ on MW and Second Virial Coeff. of PEIP1.0}

(Salt conc., $1 \mathrm{M} \mathrm{Nacl} /$ distilled/deionized $\mathrm{H}_{2} \mathrm{O}$ /polymer conc. $3.91 \mathrm{e}-3, \mathrm{~T}=25^{\circ} \mathrm{C}$ )

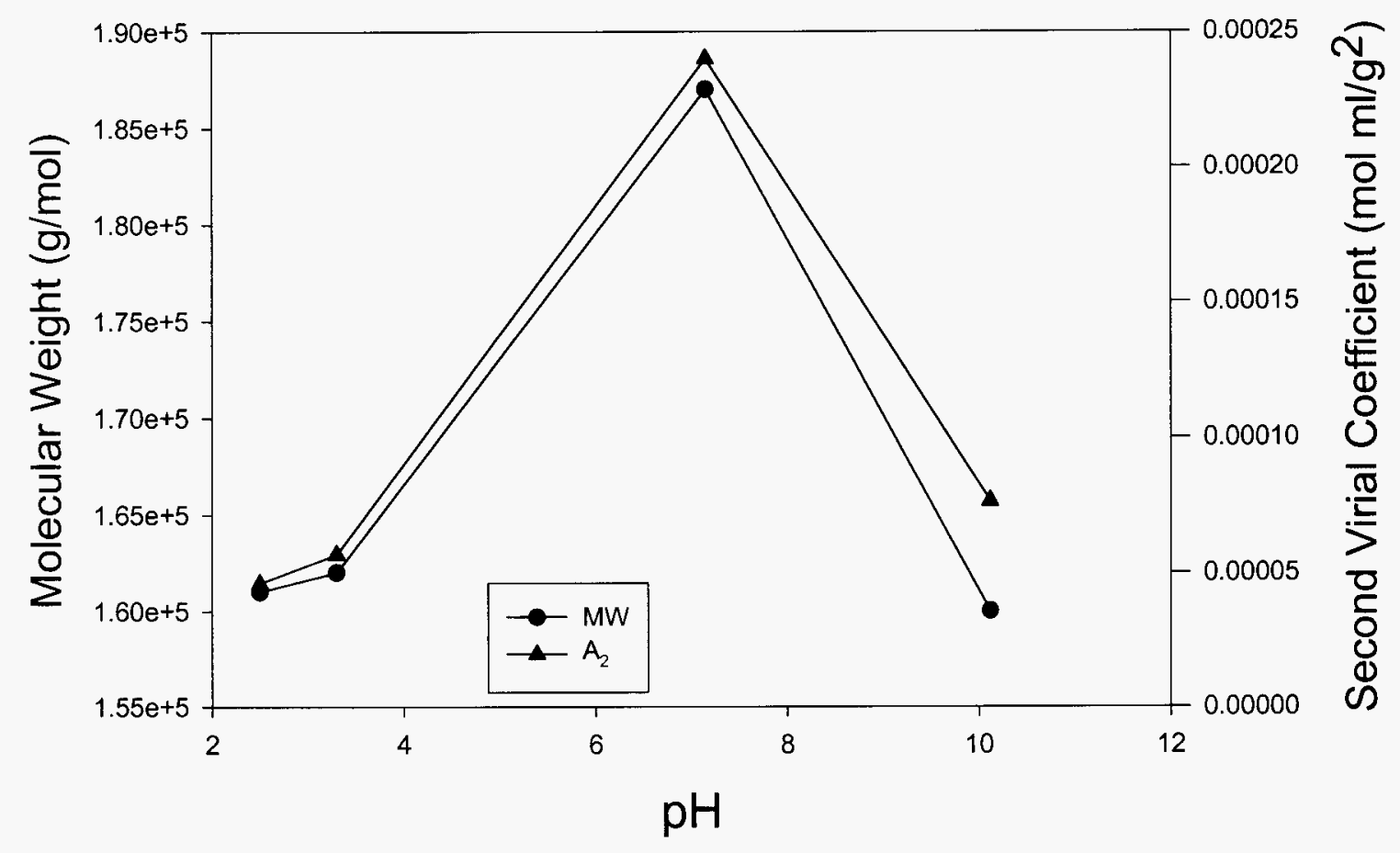

Figure 4

Table 4

\begin{tabular}{|c|c|c|}
\hline $\mathbf{p H}$ & $\mathbf{M W}(\mathbf{g} / \mathbf{m o l})$ & $\mathbf{A}_{\mathbf{2}}\left(\mathbf{m o l} \mathbf{~ m l} / \mathbf{g}^{2}\right)$ \\
\hline 2.5 & $1.61 \mathrm{e}+05$ & $4.60 \mathrm{e}-05$ \\
\hline 3.3 & $1.62 \mathrm{e}+05$ & $5.67 \mathrm{e}-05$ \\
\hline 7.15 & $1.87 \mathrm{e}+05$ & $2.40 \mathrm{e}-04$ \\
\hline 10.12 & $1.60 \mathrm{e}+05$ & $7.65 \mathrm{e}-05$ \\
\hline
\end{tabular}



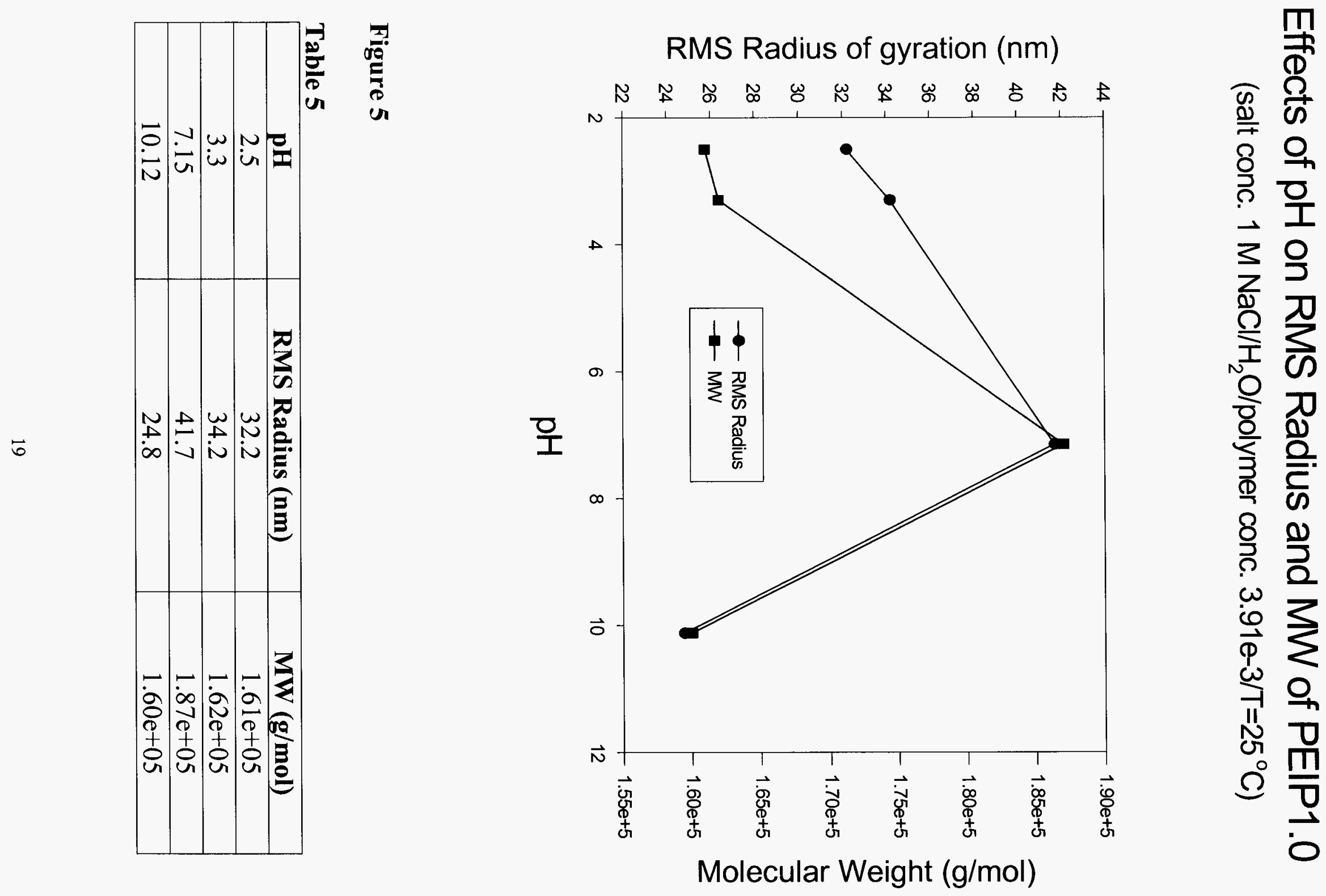
(Effects of Salt ( $\mathrm{NaCl}$ ) Conc. on MW and RMS Radius of PEIP0.75)

( $\mathrm{T}=\mathrm{oC} /$ Polymer conc. $3.875 \mathrm{e}-3 / \mathrm{pH}=7.0$ )

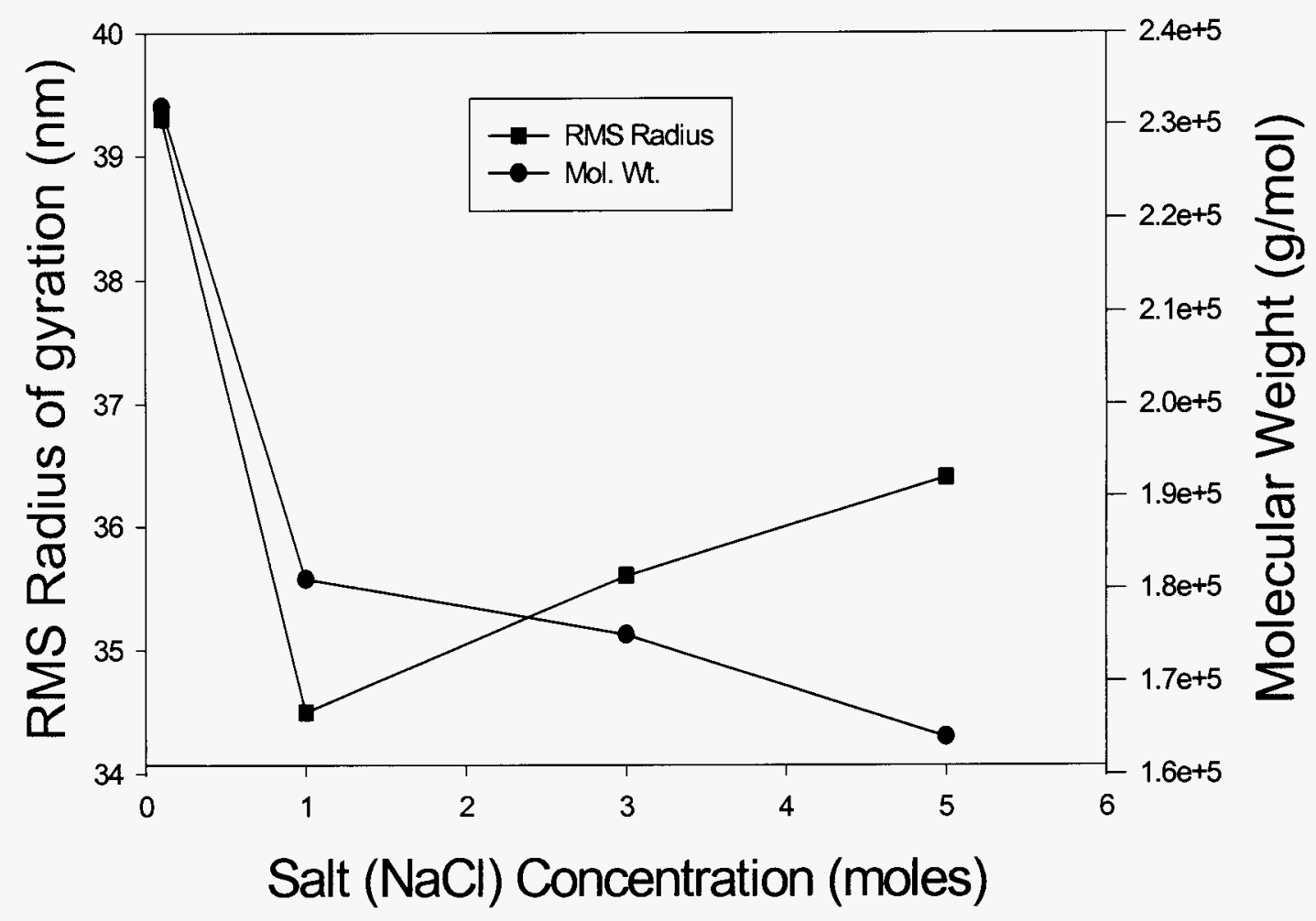

Figure 6

Table 6

\begin{tabular}{|c|c|c|}
\hline Salt Conc. (moles) & RMS Radius (nm) & MW (g/mol) \\
\hline 0.1 & 39.3 & $2.32 \mathrm{e}+05$ \\
\hline 1 & 34.5 & $1.81 \mathrm{e}+05$ \\
\hline 3 & 35.6 & $1.75 \mathrm{e}+05$ \\
\hline 5 & 36.4 & $1.64 \mathrm{e}+05$ \\
\hline
\end{tabular}


(Effects of Salt $(\mathrm{NaCl})$ Concentration on $\mathrm{MW}$ and $\mathrm{A}_{2}$ of PEIP0.75) $(\mathrm{T}=$ oC/Polymer Conc. $=3.875 \mathrm{e}-3 / \mathrm{pH}=7.0)$



Figure 7

Table 7

\begin{tabular}{|c|c|c|}
\hline Salt Conc. (moles) & Second Virial Coeff. $\left(\mathrm{A}_{2}\right)$ & $\mathrm{MW}(\mathrm{g} / \mathrm{mol})$. \\
\hline 0.1 & $2.29 \mathrm{e}-04$ & $2.32 \mathrm{e}+05$ \\
\hline 1 & $9.40 \mathrm{e}-05$ & $1.81 \mathrm{e}+05$ \\
\hline 3 & $1.89 \mathrm{e}-04$ & $1.75 \mathrm{e}+05$ \\
\hline 5 & $2.08 \mathrm{e}-04$ & $1.64 \mathrm{e}+05$ \\
\hline
\end{tabular}




\section{Effects of Polymer Conc. on MW and RMS of PEIP0.5}

\section{( $\mathrm{pH} 7.0$ /salt concentration $1 \mathrm{M} \mathrm{NaCl}$ in $\mathrm{H}_{2} \mathrm{O} / \mathrm{T}=25^{\circ} \mathrm{C}$ )}

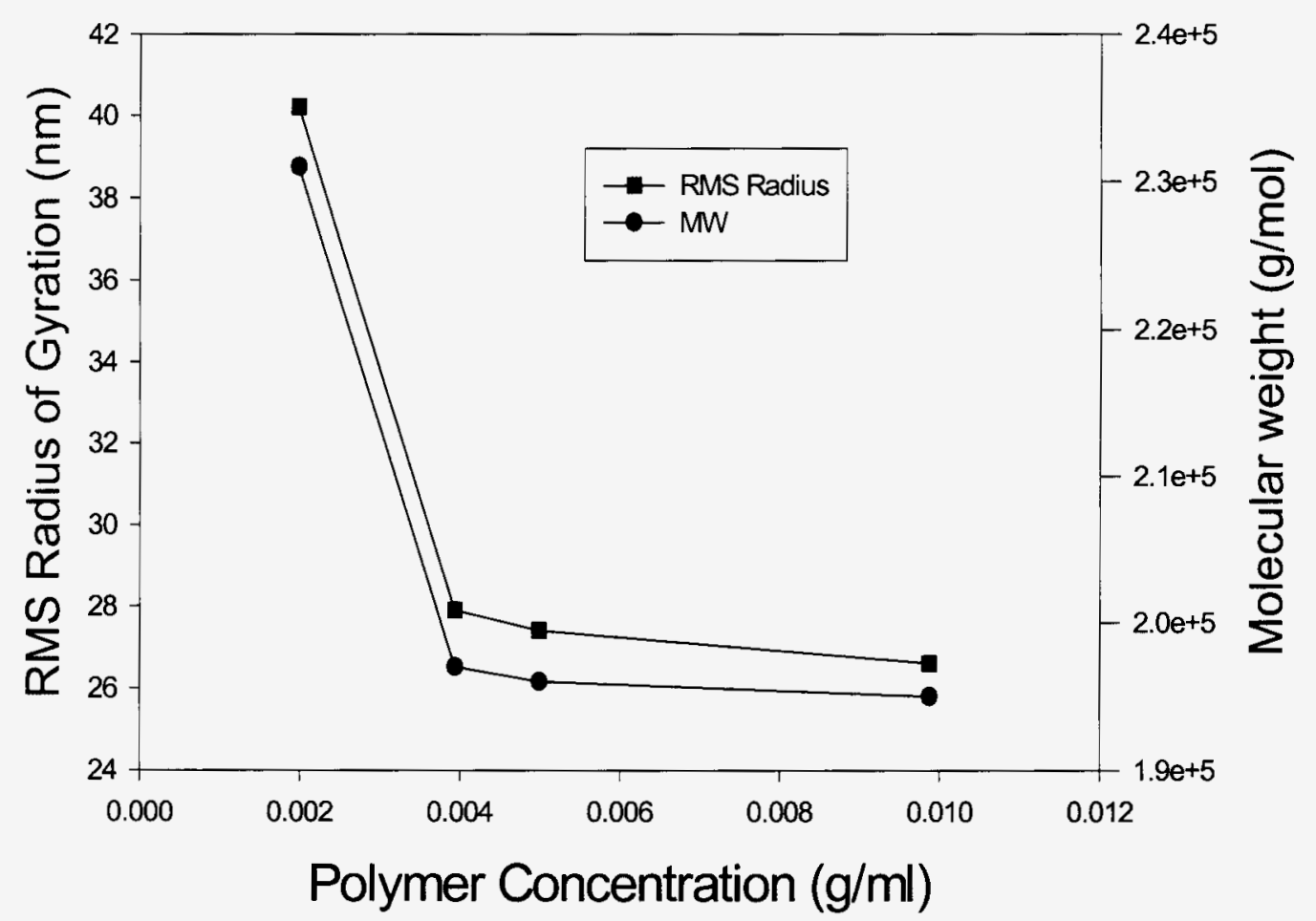

Figure 8

Table 8

\begin{tabular}{|c|c|c|}
\hline Polymer Conc. $(\mathrm{g} / \mathrm{ml})$ & RMS Radius $(\mathrm{nm})$ & $\mathrm{MW}(\mathrm{g} / \mathrm{mol})$ \\
\hline $1.98 \mathrm{e}-03$ & & \\
\hline $3.94 \mathrm{e}-03$ & & \\
\hline $5.00 \mathrm{e}-03$ & & \\
\hline $1.00 \mathrm{e}-02$ & & \\
\hline
\end{tabular}




\section{(Effects of Polymer Concentration on $\mathrm{A}_{2}$ and MW of PEIP0.5)}

$$
\left(\mathrm{pH}=7.0 / \text { salt conc. }=1 \mathrm{M} \mathrm{NaCl} / \mathrm{T}=25^{\circ} \mathrm{C}\right)
$$

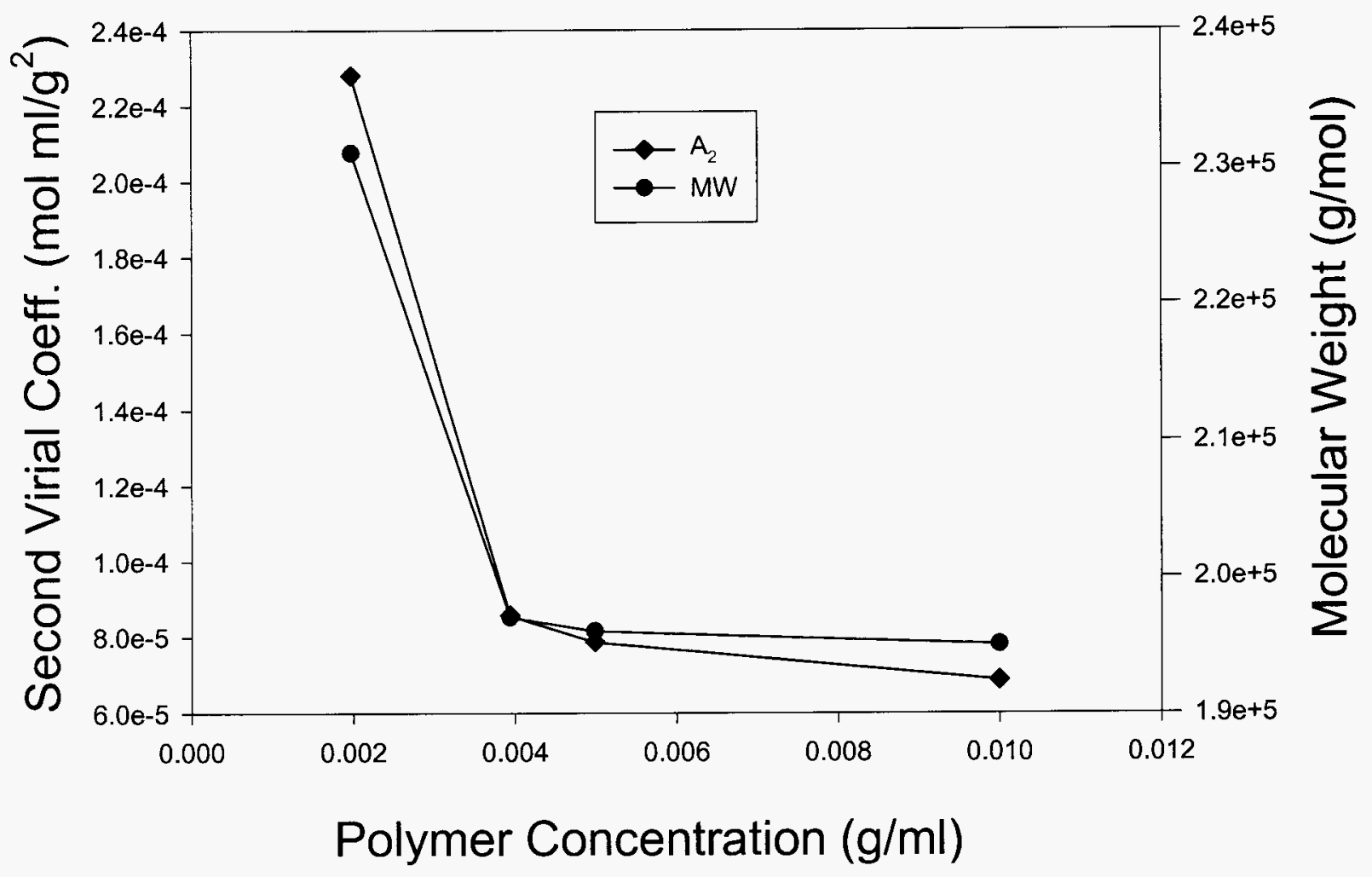

Figure 9

Table 9

\begin{tabular}{|c|c|c|}
\hline Polymer conc. (g/ml) & $A_{2}\left(\mathrm{~mol} \mathrm{ml} / \mathrm{g}^{2}\right)$ & MW (g/mol) \\
\hline $1.98 \mathrm{e}-03$ & $2.28 \mathrm{e}-04$ & $2.31 \mathrm{e}+05$ \\
\hline $3.94 \mathrm{e}-03$ & $8.57 \mathrm{e}-05$ & $1.97 \mathrm{e}+05$ \\
\hline $4.99 \mathrm{e}-03$ & $7.86 \mathrm{e}-05$ & $1.96 \mathrm{e}+05$ \\
\hline $1.00 \mathrm{e}-02$ & $6.86 \mathrm{e}-05$ & $1.95 \mathrm{e}+05$ \\
\hline
\end{tabular}



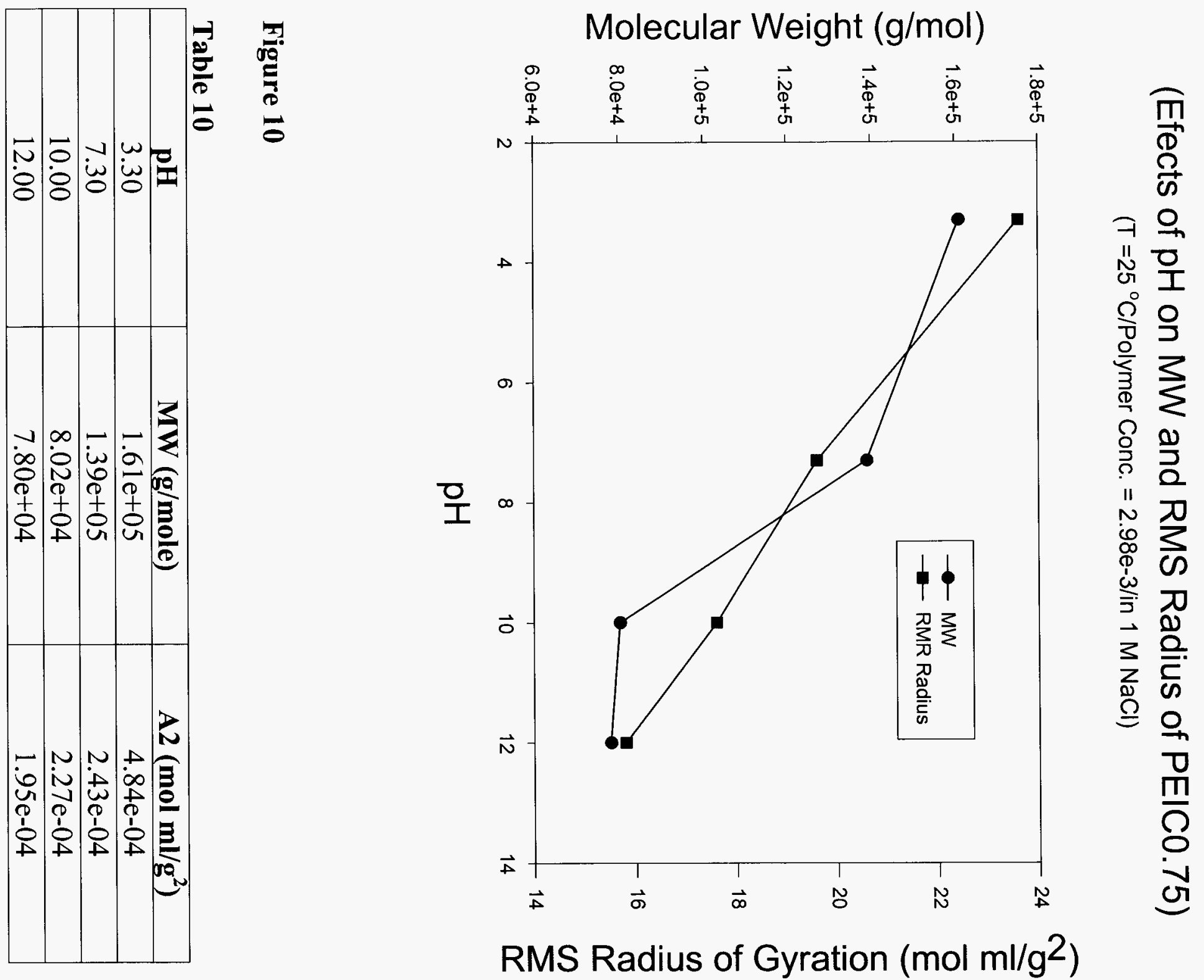


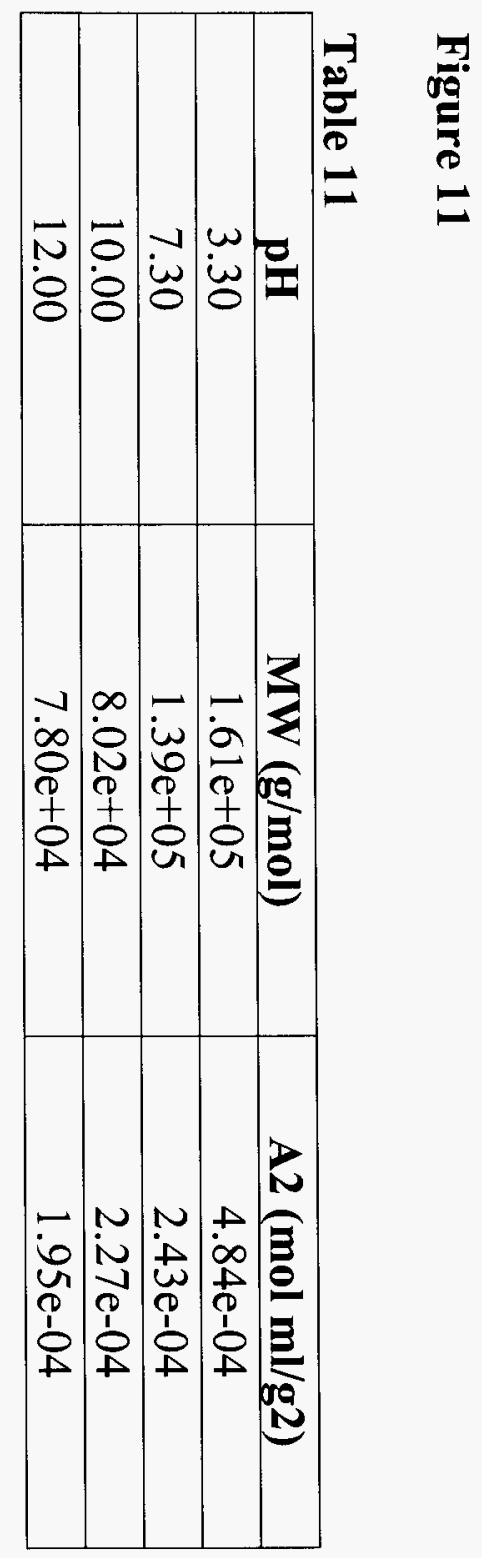

- Molecular Weight $(\mathrm{g} / \mathrm{mol})$






\section{Effects of Salt (NaCl) Conc. on RMS and MM of PEICO.25 ( $\mathrm{pH}=7.0 /$ polymer conc. $2.86 \mathrm{e}-3 / \mathrm{Temp}=25^{\circ} \mathrm{C}$ )}

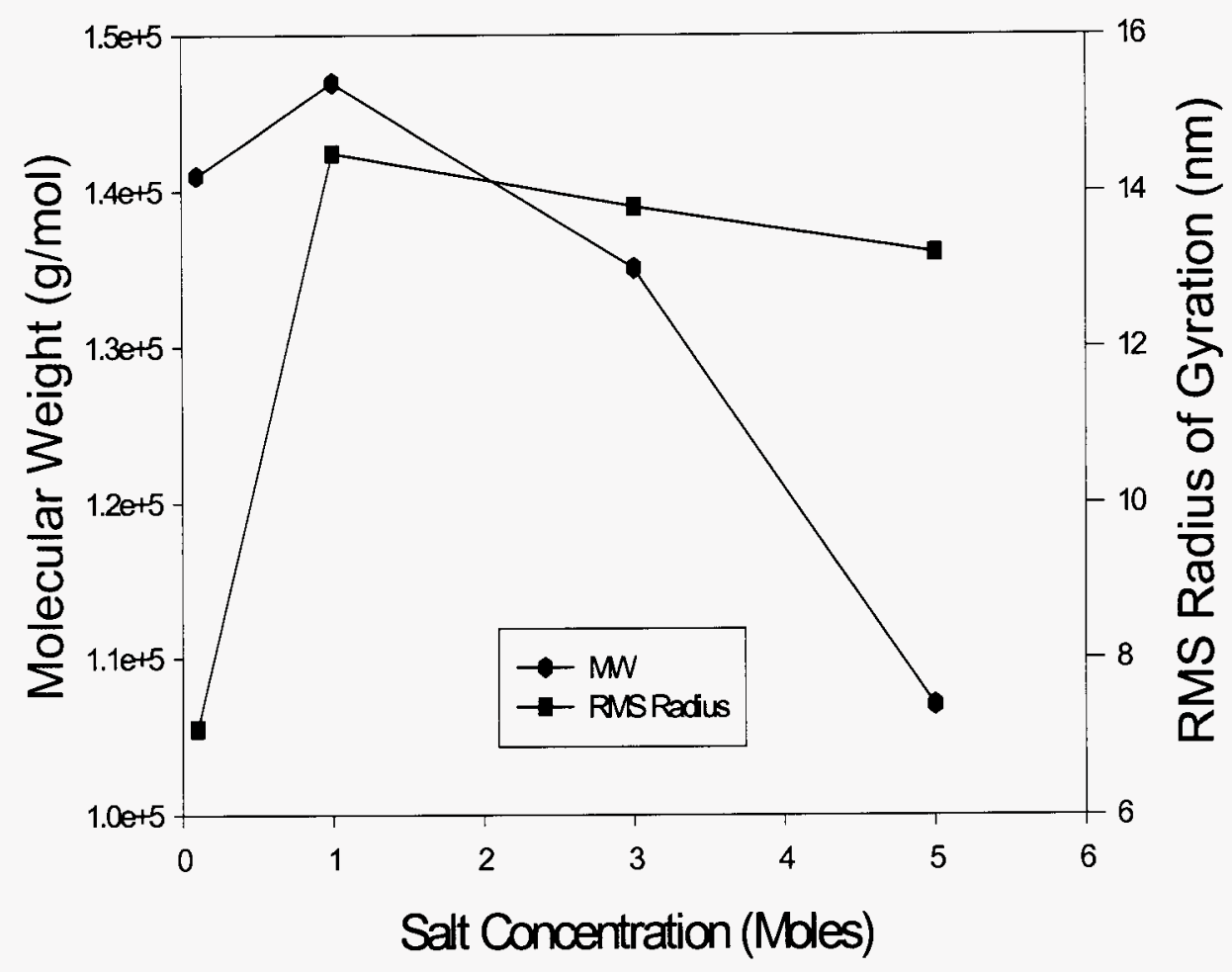

Figure 12

Table 12

\begin{tabular}{|c|c|c|}
\hline Salt Conc. (Moles) & MW (g/mol) & RMS Radius (nm) \\
\hline 0.1 & $1.41 \mathrm{e}+05$ & 7.1 \\
\hline 1.0 & $1.47 \mathrm{e}+05$ & 14.5 \\
\hline 3.0 & $1.35 \mathrm{e}+05$ & 13.8 \\
\hline 5.0 & $1.07 \mathrm{e}+05$ & 13.2 \\
\hline
\end{tabular}


Effects of Salt Conc. on MW and $\mathrm{A}_{2}$ of PEIC0.25

$\left(\mathrm{pH}=7.0 /\right.$ polymer conc. $\left.=2.86 \mathrm{e}-3 / \mathrm{T}=25^{\circ} \mathrm{C}\right)$

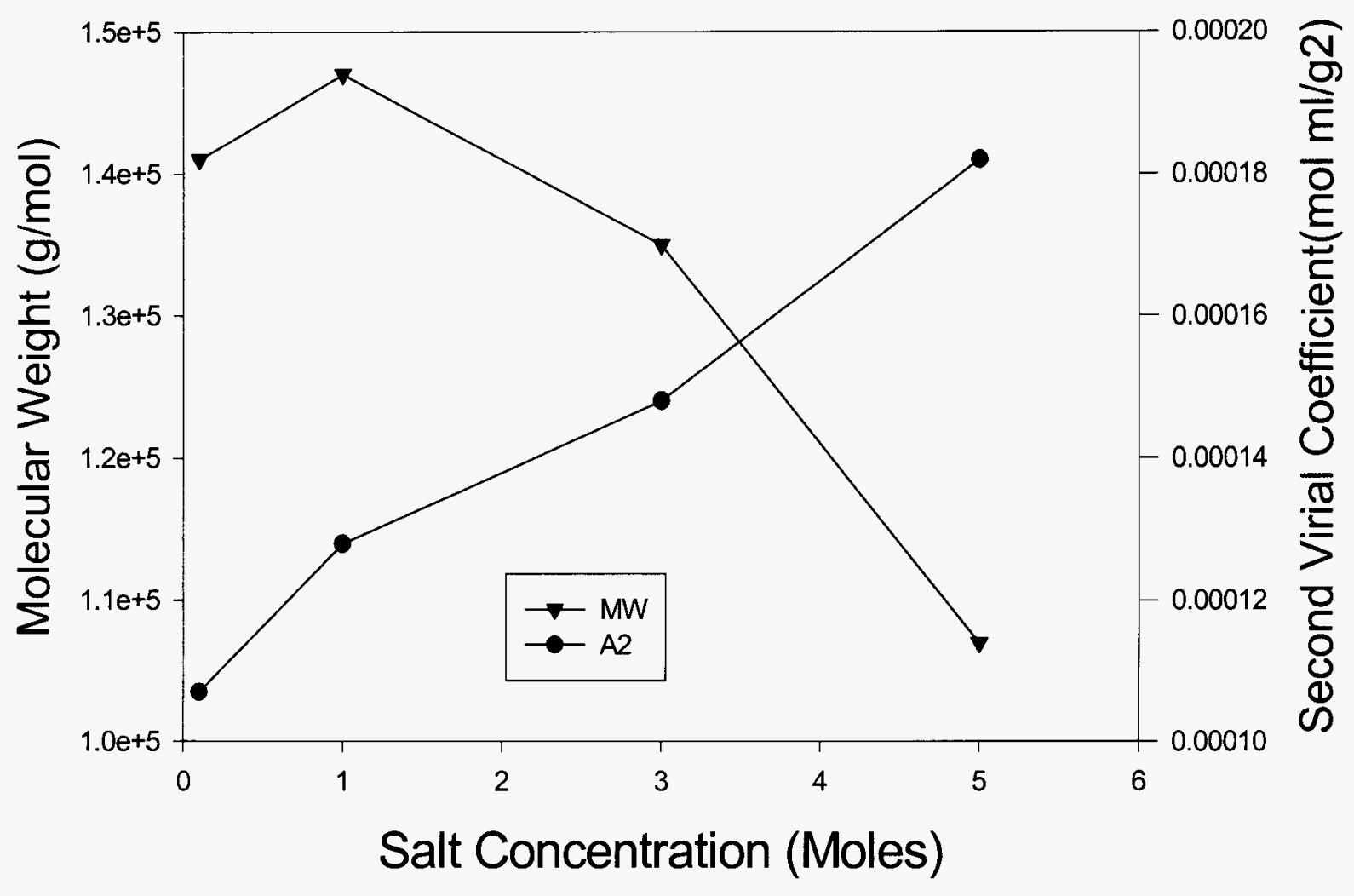

Figure 13

Table 13

\begin{tabular}{|c|c|c|}
\hline Salt Conc. (moles) & MW (g/mol) & A2 (mol ml/g2) \\
\hline 0.1 & $1.41 \mathrm{e}+05$ & $1.07 \mathrm{e}-04$ \\
\hline 1.0 & $1.47 \mathrm{e}+05$ & $1.28 \mathrm{e}-04$ \\
\hline 3.0 & $1.35 \mathrm{e}+05$ & $1.48 \mathrm{e}-04$ \\
\hline 5.0 & $1.07 \mathrm{e}+05$ & $1.82 \mathrm{e}-04$ \\
\hline
\end{tabular}




\section{Effects of Polymer Conc. on MW and Radius of PEIC1.0 ( $\mathrm{pH}=7.0 /$ salt conc. $=1 \mathrm{M} \mathrm{NaCl}$ in $\mathrm{H}_{2} \mathrm{O} / \mathrm{T}=25^{\circ} \mathrm{C}$ )}

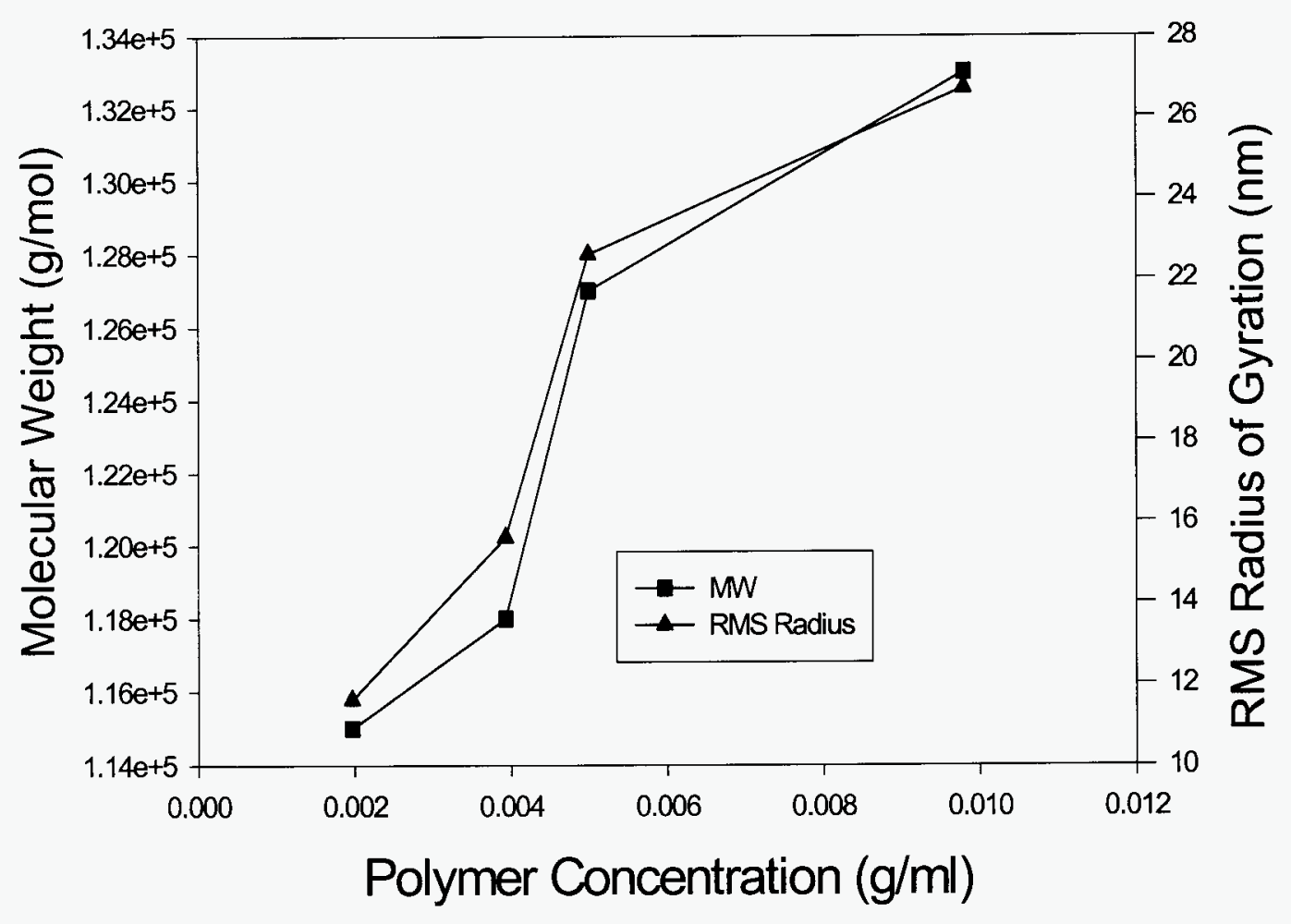

Figure 14

Table 14

\begin{tabular}{|c|c|c|}
\hline Polymer Conc.(g/ml) & MW (g/mol) & RMS Radius (nm) \\
\hline $1.97 \mathrm{e}-03$ & $1.15 \mathrm{e}+05$ & 11.6 \\
\hline $3.93 \mathrm{e}-03$ & $1.18 \mathrm{e}+05$ & 15.6 \\
\hline $4.99 \mathrm{e}-03$ & $1.27 \mathrm{e}+05$ & 22.6 \\
\hline $9.80 \mathrm{e}-03$ & $1.33 \mathrm{e}+05$ & 26.7 \\
\hline
\end{tabular}




\section{Effects of Polymer Conc. on MW and A2 of PEIC1.0 ( $\mathrm{pH}=7.0$ /salt conc. $1 \mathrm{M} \mathrm{NaCl}$ in $\mathrm{H}_{2} \mathrm{O} / \mathrm{T}=25^{\circ} \mathrm{C}$ )}



Figure15

Table 15

\begin{tabular}{|c|c|c|}
\hline Polymer Conc. $(\mathbf{g} / \mathbf{m l})$ & MW $\mathbf{( g / m o l})$ & A2 $\mathbf{( m o l ~} \mathbf{~ m l} / \mathbf{g} 2)$ \\
\hline $1.97 \mathrm{e}-03$ & $1.15 \mathrm{e}+05$ & $2.14 \mathrm{e}-04$ \\
\hline $3.93 \mathrm{e}-03$ & $1.18 \mathrm{e}+05$ & $1.71 \mathrm{e}-04$ \\
\hline $4.99 \mathrm{e}-03$ & $1.27 \mathrm{e}+05$ & $2.26 \mathrm{e}-04$ \\
\hline $9.80 \mathrm{e}-03$ & $1.33 \mathrm{e}+05$ & $2.50 \mathrm{e}-04$ \\
\hline
\end{tabular}




\section{Report on ${ }^{113} \mathrm{Cd}$ NMR studies of the Metal-binding characteristics of Polyethylenimine (PEI)}

FROM: Sonny A. Ekhorutomwen and Samuel P. Sawan, Department of Chemistry, University of Massachusetts, Lowell, 1 University Avenue, Lowell, MA 01854

TO: $\quad$ Barbara F. Smith, Los Alamos National Laboratory, $127446^{\text {th }}$ Street, Los Alamos, NM 07594

\section{INTRODUCTION}

The selective removal and/or recovery of hazardous and valuable metal ions and radionuclides from various dilute aqueous streams are major concerns to the United States Government and environmentalists. Heavy metal contamination of the environment is caused by the wide usage of heavy metals in industries to meet the demand of modern society. However, polyethylenimine (PEI) a water-soluble polymer, has been found to have a great affinity to binding with metals, principally due to its polyelectrolyte character as well as their large macromolecular sizes which make them very useful in sequestering metal ions from dilute solutions. Metal-ion NMR is a useful tool in probing specific metal binding sites of macromolecules such as metalloproteins due to the sensitivity of these nuclei to their coordination environments. ${ }^{113} \mathrm{Cd}$ NMR spectroscopy has been used in studies of the structure and dynamics of inorganic and bioinorganic molecules ${ }^{1-4}$. The utility of ${ }^{113} \mathrm{Cd}$ NMR as a metallobioprobe is due to the ability of the Cadmium (II) ion to form complexes over a range of conformation and ligand numbers. ${ }^{113} \mathrm{Cd}$ atom has a spin of $1 / 2$ with no quadrupolar contribution to cause NMR relaxation, which broadens the NMR signals. A chemical shift range of over 900 ppm has been observed for ${ }^{113} \mathrm{Cd}$, depending on the nature, number and geometric arrangement of the coordinated ligands ${ }^{5-10}$. Freeland et al. ${ }^{11}$, have also demonstrated the high affinity of polyethylenimine for mercury. Also there have been several reports of the ability of protein fibers to absorb mercury from aqueous solution ${ }^{12-14}$, and the possibility of using them in effluent purification processes or for clinical purposes ${ }^{15}$. Likewise, amine-modified cotton could adsorb mercury $\left(\mathrm{Hg}^{2+}\right)$ from solutions ${ }^{16,17} \cdot \mathrm{Hg}^{2+}$ and $\mathrm{Cd}^{2+}$ ions have strong affinity for various chemical functional groups such as 
carboxylate groups, amines, phenolic-OH groups, etc. Therefore, the use of cadmium and mercury NMR is very important in the study of the binding characteristics of PEI to metals.

\section{EXPERIMENTAL}

\subsection{Materials:}

Cadmium perchlorate EDTA, Cadmium oxide, Cadmium sulfate anhydrous and Cadmium chloride were purchased from Alfa Aesar, Deuterium oxide $\left(D_{2} 0,99.9 \%\right)$ deuterium chloride (DCl, 99.5\%), Sodium deuteroxide (NaOD, 99.5\%) were bought from Cambrigde Isotopes, Andover, Massachusetts. Poly(acrylic acid) (PAA, MW = 450.000), Polyethylenimine (PEI, MW = 10,000), Poly(methyacrylic acid, PMAA), Poly(methyacrylamide) PMA, water-soluble, hydrophilic, were purchased from Polysciences, Inc. Mercury (II) nitrate monohydrate, $15.5 \mathrm{~N}$ perchloric acid, potassium hydrogen phthalate, picolinic acid, $0.987 \mathrm{~N} \mathrm{NaOH}, 0.953 \mathrm{~N} \mathrm{HCl}, \mathrm{NaOH}$ pellets, 2propanol, Ethylenediamine, glycine and succinic acid were purchased from Aldrich Chemical Company.

\subsection{Sample Preparation:}

\subsubsection{Preparation of $0.3 \mathrm{M} \mathrm{Cd}\left(\mathrm{ClO}_{4}\right)_{2}$ solution:}

This was done by dissolving $1.251 \mathrm{~g}$ of $\mathrm{Cd}\left(\mathrm{ClO}_{4}\right)_{2} \cdot 6 \mathrm{H}_{2} \mathrm{O}$ in $10 \mathrm{ml}$ of $0.1 \mathrm{M}$ perchloric acid, to give $0.3 \mathrm{M} \mathrm{Cd}\left(\mathrm{ClO}_{4}\right)_{2}$ in $0.1 \mathrm{M}$ perchloric acid.

\subsubsection{Preparation of $\mathrm{CdCl}_{2}$ solution:}

This was done by dissolving $65 \mathrm{mg}$ of $\mathrm{CdO}$ (12.86\% natural abundance) in $2 \mathrm{ml}$ of hot concentrated $\mathrm{HCl}$ acid. The aliquot was evaporated on a hot plate until it was dried out and the sediment turned to white powder. The sediment was then dissolved in $3.5 \mathrm{ml}$ of $\mathrm{D}_{2} \mathrm{O}$.

mg of polyethylene (PEIC or PEIP) was dissolved in $1 \mathrm{ml}$ of the $\mathrm{CdCl}_{2}$ solution, for the NMR measurements. 


\section{RESULTS AND DISCUSSION}

Results presented here collectively add up to a summary of the work done on the binding characteristics of PEI, PEIC and PEIP with ${ }^{113}$ Cadmium.

\subsection{Model Compound Studies}

This work was a two-phase project. The first was to measure the chemical shifts of Cd-Polymers (PEIC and PEIP). The second phase was measuring the chemical shifts of well-defined molecular analogs of expected binding sites (model compounds/structures). Understanding the chemical shift anisotropy of Cadmium was necessary to understanding the chemical environments of the metal. This is specifically important in chelating environments where the nature of the ligands can change depending on a lot of factors. Some model compounds were studied in relation to their binding with cadmium. These are:

1. Ethylenediamine (2 amines)

2. Glycine, aminocarboxylate

3. Succinic acid

4. Polyacrylamide

5. Leucinamid hydrochloride

6. Butylamine (1 amine)

7. 3-Diamino-2-hydroxypropane

The chemical shift values of the Cadmium-PEI complex are shown in Figure 1 below. Two resonance values are shown at $305 \mathrm{ppm}$ and $320 \mathrm{ppm}$. PEI is a purified polyethylenimine with only amine groups and no carboxylate groups. The chemical shift values move downfield with only amine groups present. As the polymer becomes functionalized, e. g. with addition of carboxylate groups, the resonances shift upfield. Figures 2 and 3 show the chemical shift values for the functionalized polymers coordinated to ${ }^{113} \mathrm{Cadmium}$. As the percentage modification increases from $0 \%$ to $100 \%$ as the case may, the chemical shifts move upfield. ${ }^{113} \mathrm{Cd}^{2+}$ ion is an excellent metal ion probe due to its ability to form complexes with many different conformations and ligand 
numbers ${ }^{18}$. Furthermore, the ${ }^{113} \mathrm{Cd}^{2+}$ chemical shift covers a wide range from about 800 to $-200 \mathrm{ppm}$, and the nature of the coordinating ligands and their coordination numbers are strongly reflected in the chemical shift ${ }^{19-21}$. ${ }^{113} \mathrm{Cd}$ chemical shift in solutions of cadmium-containing coordination compounds is reflective of the directly bonded heteroatom of the ligand. In particular, ligands that bind through oxygen cause increased shielding of the $\mathrm{Cd}$ nucleus, while ligands that bind through nitrogen produce deshielding of the $\mathrm{Cd}$ nucleus. Ligands that bind via sulfur produce very large deshielding (downfield chemical shifts). This might partially explain the chemical shifts of the different levels of functionalization. Since the binding sites of Cadmium to PEIC are through oxygen in the carboxyl moieties, explains while the $75 \%$ and $100 \%$ modified PEIC are upfield to the $25 \%$ and $50 \%$ PEIC.

The use of Model compounds to investigate metal-binding characteristics of polymers is a standard procedure in NMR spectroscopy. Recently, an investigation of $\mathrm{Cd}$ (II)-carboxylate systems (mono- and di-carboxylic acids) in aqueous solution was carried out by Chung and $\mathrm{Moon}^{22}$, using ${ }^{113} \mathrm{Cd}$ NMR spectroscopy. In this study, they found out that, in $\mathrm{Cd}(\mathrm{II})$-carboxylate systems, an increase in the carboxylate-to-Cadmium ratio caused the chemical shift to move towards an upfield region: the cadmium ion becomes more shielded when coordinated water molecules are displaced by carboxylates. Figures 4 to 10 show the chemical shift values for Cd-Model compound complexes. Since PEI is basically an amine polymer, the critical requirement for a model compound was that it should have an amine group in most cases. Functionalization introduces carboxylate groups and it was important therefore to also use model compounds with this group. The chemical shift position is reflective of the number of amine or carboxylate groups present. Butylamine (with one amine) has shift value at $267 \mathrm{ppm}$ (Fig. 5).

Ethylenediamine with two amine groups has chemical shift at $351 \mathrm{ppm}$ (Fig. 10). But introduction of carboxylate groups moves the chemical shift upfield, for example, glycine has one amine and a carboxylate group and has its chemical shift at $43.17 \mathrm{ppm}$. The chemical shifts for the model compounds are given in Table 3 . 


\section{CONCLUSIONS}

Polyethylenimine (PEI), a water-soluble polymer has been found to have great affinity to binding with metals, due to its polyelectrolyte character and large macromolecular size. PEI binds readily with $\mathrm{Cd}$ (II), $\mathrm{Hg}$ (II), etc., and therefore very useful for sequestering metal ions from aqueous streams. ${ }^{113} \mathrm{Cd}$ chemical shift in solutions of cadmium-containing coordination compounds is reflective of the directly bonded heteroatom of the ligand. In particular, ligands that bind through oxygen cause increased shielding of the Cd nucleus, while ligands that bind through nitrogen produce deshielding of the $\mathrm{Cd}$ nucleus. Ligands that bind via sulfur produce very large deshielding (downfield chemical shifts).

\section{REFERENCES}

1. Boulanger, Y., Armitage, I. M., Miklossy, K. A., Winge, D. R., J. Biol. Chem. 257, 13717 (1982).

2. Bobsein, B. R., Myers, R. J., J. Am. Chem. Soc., 102, 2454 (1980).

3. Otoves, J. D., Armitage, I. M., Biochemistry, 19, 4031 (1980).

4. Evelhoch, J. L., Bocain, D. L., Sudmeier, Biochemistry, 20, 4951 (1981).

5. Ellis, P. D., Science, 221, 1141 (1983).

6. Summers, M. F., Coord. Chem. Rev. 86, 43 (1988).

7. Cardin A. D., Ellis, P. D., Odom, J. D., Howard, J. W., J. Am. Chem. Soc. 97, 1672 (1975).

8. Haberkorn, A. R., Que, I., Gillum, W. O., Holm, R. H., Liu, C. S., Lord, R. C., Inorg. Chem. 15, 2408 (1976).

9. Jensen, C. F., Deshmukh, Jacobsen, H. J., Inners, R. R., Ellis, P. D. J. Am. Chem. Soc. 103, 3659 (1981).

10. Rodesiler, P. F., Amma, E. L., J. Chem. Soc. Chem. Commun. 182 (1982).

11. Freeland, Graeme N., Hoskinson, Ronald M., Mayfield, Robert J., Environ. Sci. Technol., 8(10), 942 (1974).

12. Friedman, M., Masari, M. S., J. Appl. Polymer Sci., 17, 2183 (1973).

13. Friedman, M., Waiss, A. C., Environ. Sci. Technol. 6, 457 (1972). 
14. Friedman M., Harrison, C. S., Ward, H. W., Lundgren, H. P. J. Appl. Polymer Sci., 17, 377 (1973).

15. Takahashi, H., Hirayama, K., Nature, 232, 201(1971).

16. Roberts, E. J., Rowlands S. P., Textile Res. J., 41, 864 (1971).

17. Roberts, E. J., Rowlands S. P., Environ. Sci. Technol. 7, 552, (1973).

18. C. K. Larvine, A. Rogers, M. Morton, W. R. Carper, Environ. Sci. Technol., 30, 2828-2831, 1996

19. M. F. Summers, Coord. Chem. Rev., 86, 43-134, 1988

20. C. Johansson, T. Drakenberg, Annu Rev. NMR Spectrosc., 22, 1-59, 1989.

21. K. H. Chung, S. W. Rhee, H. S. Shin, C. H. Moon, Can. J. Chem., 74, 1360-1365, 1996.

22. K. H. Chung, C. H. Moon, J. Chem. Soc. Dalton Trans. 75, 1996.

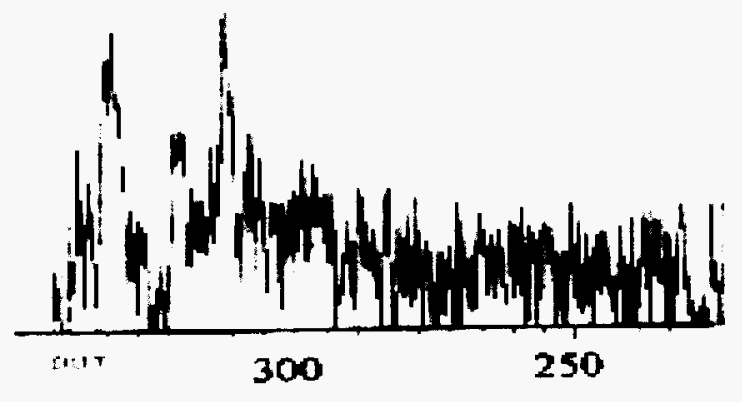

PPM

Figure 1. Shows the chemical shifts of the Cadmium-PEI complex. The purified PEI has two chemical shift values at 305 and 320 ppm. 

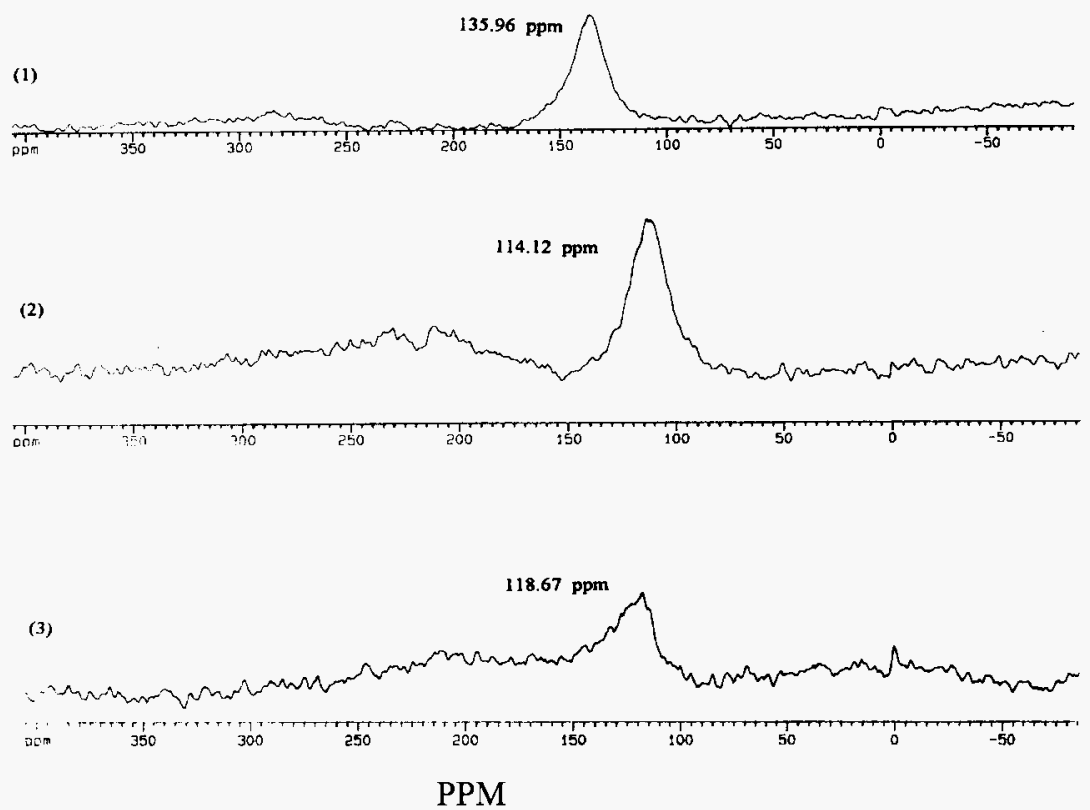

Figure 2. ${ }^{113} \mathrm{Cd}$ NMR spectrum of ${ }^{113} \mathrm{Cd}$-PEIP complexes. Cd-PEIP complexes have chemical shifts at (1) $135.96 \mathrm{ppm}$ for Cd-PEIP 0.25 complex, (2) $114.12 \mathrm{ppm}$ for CdPEIP0.50 complex and (3) 118.67 for Cd-PEIP 0.75 complex. 

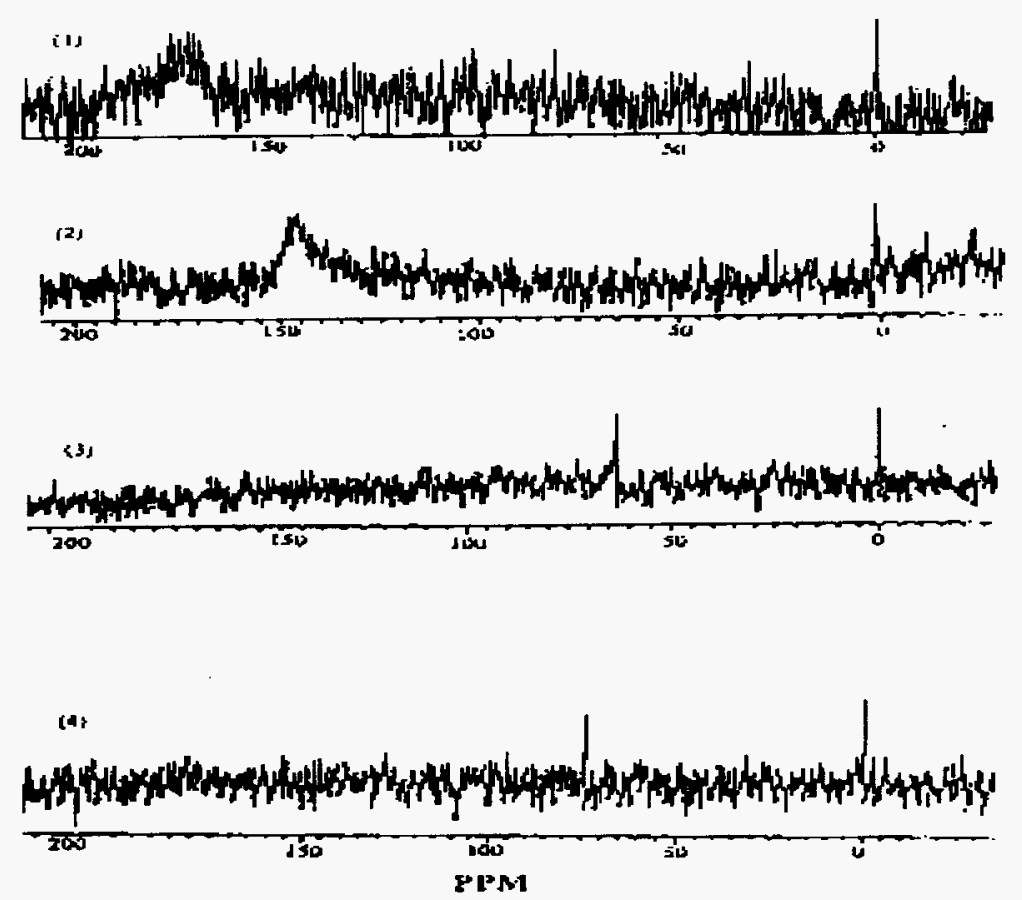

Figure 3. The ${ }^{113} \mathrm{Cd}-\mathrm{PEIC}$ complex NMR spectra of different levels of functionalization of PEIC (Carboxyl-modified PEI), where (1) $25 \%$, (2) $50 \%$, (3) $75 \%$ and (4) $100 \%$ modified.

\section{MODEL COMPOUNDS}

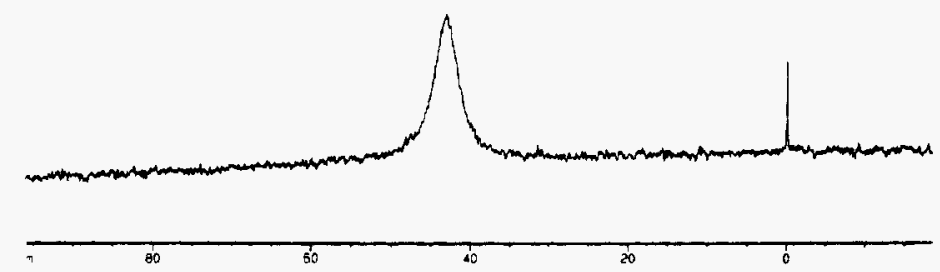

Figure 4. The ${ }^{113} \mathrm{Cd}-$ Glycine $\left({ }^{113} \mathrm{Cd}-\mathrm{Gly}\right)$ spectrum. The chemical shift for Gly is 43.17 ppm. 


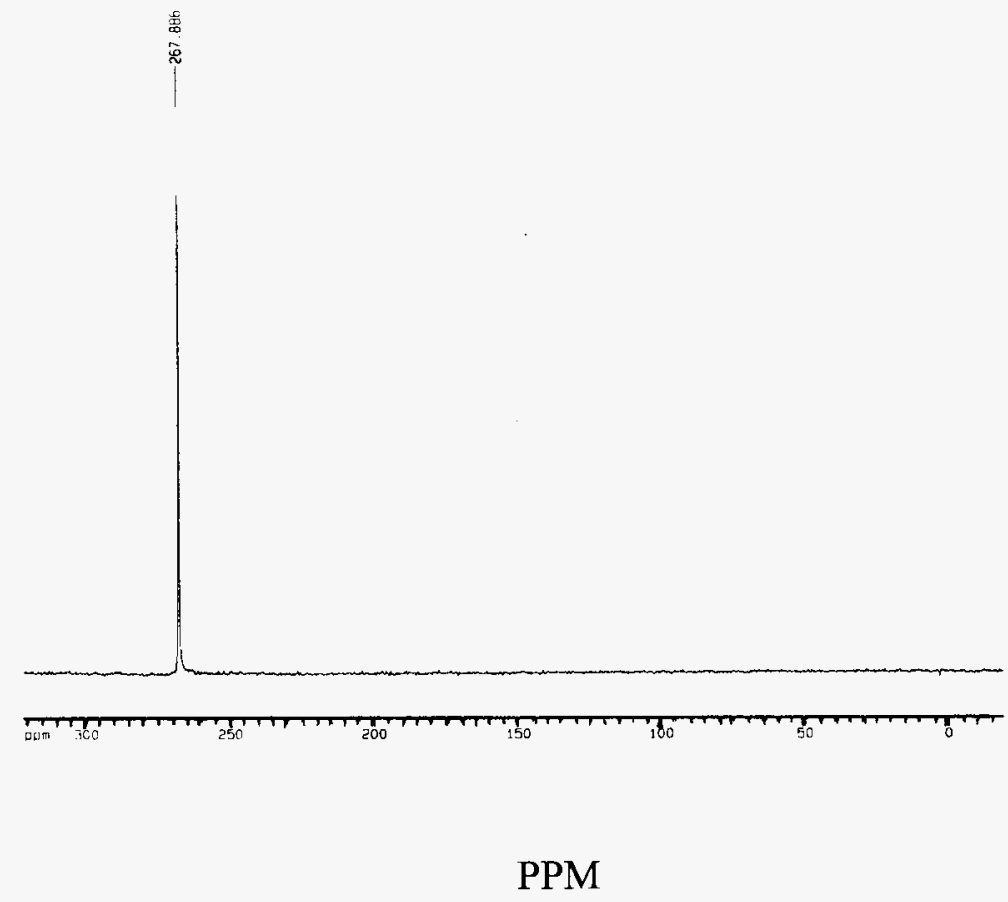

Figure 5. Shows the chemical shift of ${ }^{113} \mathrm{Cd}$-Butylamine complex with $\delta=267.87 \mathrm{ppm}$.

s

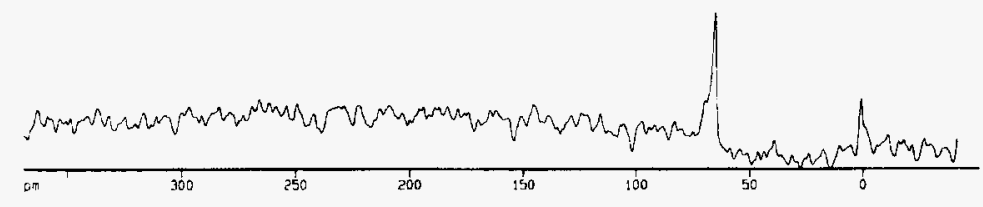

PPM

Figure 6. ${ }^{113} \mathrm{Cd}$ NMR chemical shift of ${ }^{113} \mathrm{Cd}$-Polymethyacrylamide (PMA) at $65.48 \mathrm{ppm}$ 


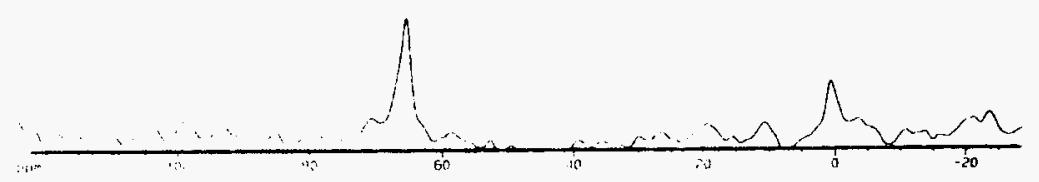

PMM

Figure 7. The chemical shift of ${ }^{113} \mathrm{Cd}-\mathrm{SUC}$ (Cd-Succinic acid) at $45.41 \mathrm{ppm}$.

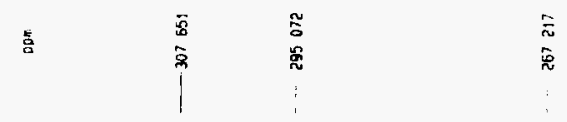

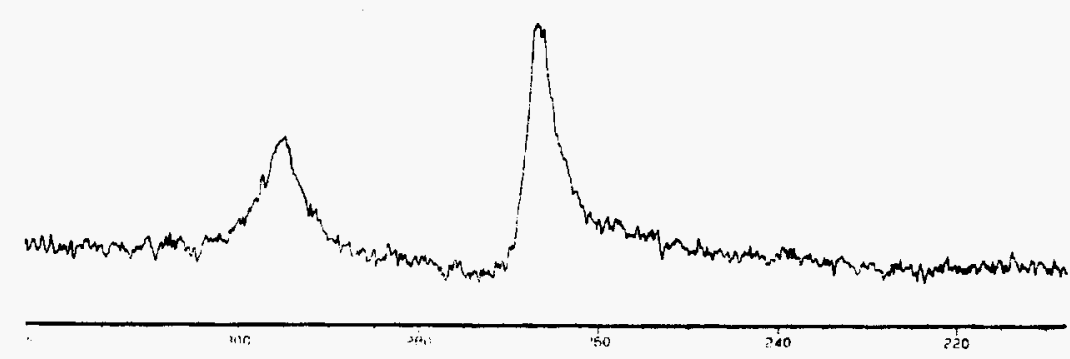

PPM.

Figure 8. Shows the chemical shift values of ${ }^{113} \mathrm{Cd}-\mathrm{I}$, 3-diamino 2-hydroxypropane (DHP), at $260 \mathrm{ppm}$ and $290 \mathrm{ppm}$. 


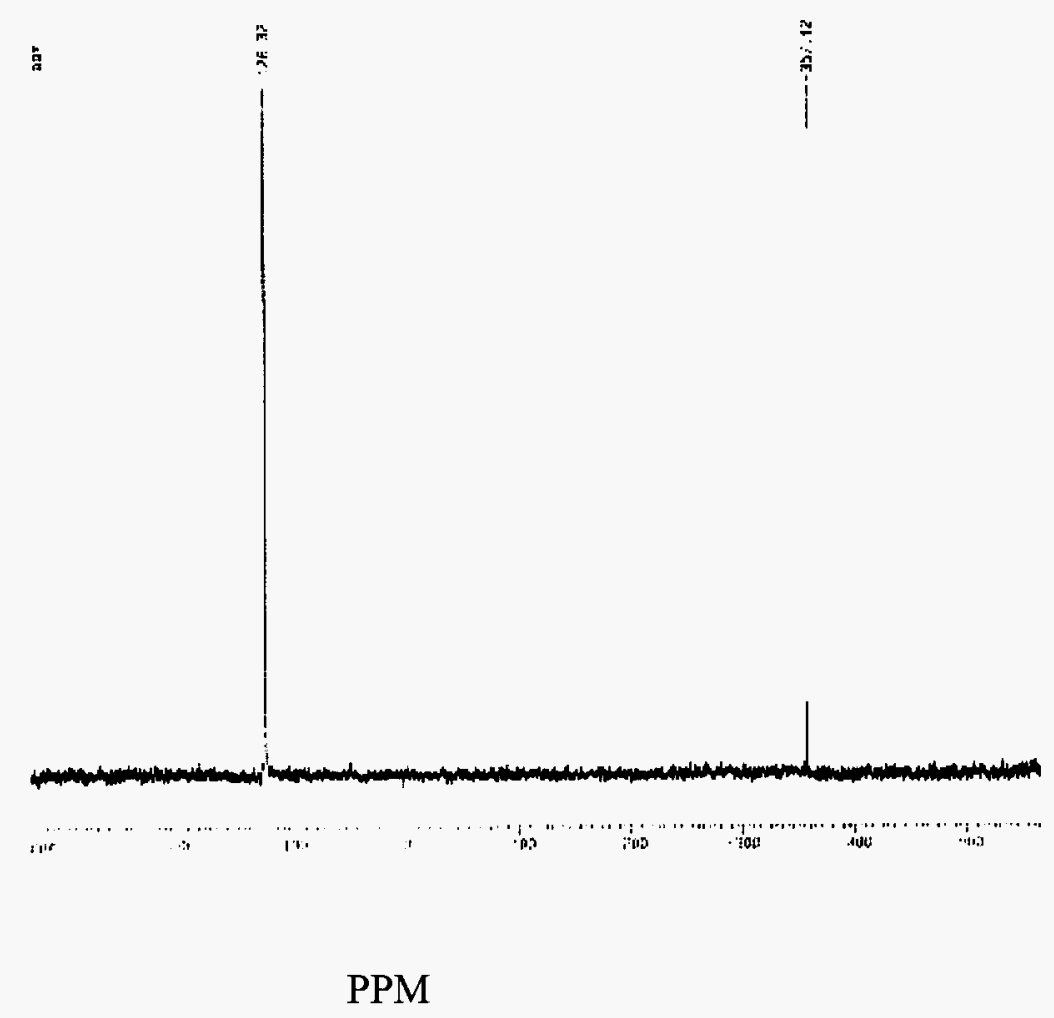

Figure 9. Chemical shifts of ${ }^{113} \mathrm{Cd}-$ Leucinamide( $\left.\mathrm{HCl}\right)$ at 126.3 and $-357.1 \mathrm{ppm}$



Figure 10. $113 \mathrm{Cd}$ binding with Ethylenediamine (EDA) with the chemical shift value $\delta=351.106 \mathrm{ppm}$. 
Table 1. Chemical shifts for PEIC polymers

\begin{tabular}{|c|c|}
\hline \% FUNCTIONALIZATION & NMR CHEMICAL SHIFT VALUES $(\delta)$ \\
\hline PEIC $0.25(25 \%)$ & 175.00 \\
\hline PEIC $0.50(50 \%)$ & 146.03 \\
\hline PEIC $0.75(75 \%)$ & 63.74 \\
\hline PEIC $1.00(100 \%)$ & 74.50 \\
\hline
\end{tabular}

Table 2. Chemical shift for PEIP polymers

\begin{tabular}{|l|l|}
\hline \% FUNCTIONALIZATION & NMR CHEMICAL SHIFT VALUES $(\delta)$ \\
\hline PEIP $0.25(25 \%)$ & 135.96 \\
\hline PEIP $0.50(50 \%)$ & 114.12 \\
\hline PEIP $0.75(100 \%)$ & 118.67 \\
\hline UNMODIFIED PEI & 305,320 \\
\hline
\end{tabular}

Table 3. Model compounds Chemical Shifts

\begin{tabular}{|c|c|}
\hline MODEL COMPOUNDS & ${ }^{113} \mathrm{Cd}-$ Model compd $\delta$ (ppm) \\
\hline Polymethacrylate (PMA) & 65.48 \\
\hline Glycine (GLY) & 43.17 \\
\hline Succinic Acid (SUC) & 45.41 \\
\hline Leucinamide hydrochloride (LEU) & $126.3,-357.1$ \\
\hline Buthylamide (BTA) & 267.87 \\
\hline 3-Diamino, 2-hydroxypropane & 260,290 \\
\hline Ethylenediamine (EDA) & 351.10 \\
\hline
\end{tabular}




\title{
${ }^{113} \mathrm{Cd}$ NMR studies of the Metal-binding characteristics of Polyethylenimine (PEI)
}

\author{
Sonny A. Ekhorutomwen and Samuel P. Sawan \\ Department of Chemistry, \\ University of Massachusetts, Lowell \\ 1 University Avenue, Lowell, MA 01854 \\ Barbara F. Smith \\ Los Alamos National Laboratory \\ $127446^{\text {th }}$ Street, Los Alamos, NM 07594
}

\begin{abstract}
Polyethylenimine (PEI), a water-soluble polymerhas been found to have great affinity to binding with metals, due to its polyelectrolyte character and large macromolecular size. PEI binds readily with $\mathrm{Cd}$ (II), $\mathrm{Hg}$ (II), etc., and therefore very useful for sequestering metal ions from aqueous streams.
\end{abstract}

\section{INTRODUCTION}

The selective removal and/or recovery of harzadous and valuable metal ions and radionuclides from various dilute aqueous streams are major concerns to the United States Government and environmentalists. Heavy metal contamination of the environment is caused by the wide usage of heavy metals in industries to meet the demand of modern society. However, polyethylenimine (PEI) a water-soluble polymer, has been found to have a great affinity to binding with metals, principally due to its polyelectrolyte character as well as their large macromolecular sizes which make them very useful in sequestering metal ions from dilute solutions. Metal-ion NMR is a useful tool in probing specific metal binding sites of macromolecules such as metalloproteins due to the sensitivity of these nuclei to their coordination environments. ${ }^{113} \mathrm{Cd}$ NMR 
spectroscopy has been used in studies of the structure and dynamics of inorganic and bioinorganic molecules ${ }^{1-4}$. The utility of ${ }^{113} \mathrm{Cd}$ NMR as a metallobioprobe is due to the ability of the Cadmium (II) ion to form complexes over a range of conformation and ligand numbers. ${ }^{113} \mathrm{Cd}$ atom has a spin of $1 / 2$ with no quadrupolar contribution to cause NMR relaxation, which broadens the NMR signals. A chemical shift range of over 900 ppm has been observed for ${ }^{113} \mathrm{Cd}$, depending on the nature, number and geometric arrangement of the coordinated ligands ${ }^{5-10}$. Freeland et al. ${ }^{11}$, have also demonstrated the high affinity of polyethylenimine for mercury. Also there have been several reports of the ability of protein fibers to absorb mercury from aqueous solution ${ }^{12-14}$, and the possibility of using them in effluent purification processes or for clinical purposes ${ }^{15}$. Likewise, amine-modified cotton could adsorb mercury $\left(\mathrm{Hg}^{2+}\right)$ from solutions ${ }^{16,17} . \mathrm{Hg}^{2+}$ and $\mathrm{Cd}^{2+}$ ions have strong affinity for various chemical functional groups such as carboxylate groups, amines, phenolic $-\mathrm{OH}$ groups, etc. Therefore, the use of cadmium and mercury NMR is very important in the study of the binding characteristics of PEI to metals.

\section{EXPERIMENTAL}

Materials: Cadmium perchlorate EDTA, Cadmium oxide, Cadmium sulfate anhydrous and Cadmium chloride were purchased from Alfa Aesar, Deuterium oxide $\left(D_{2} 0,99.9 \%\right)$ deuterium chloride ( $\mathrm{DCl}, 99.5 \%)$, Sodium deuteroxide $(\mathrm{NaOD}, 99.5 \%)$ were bought from Cambridge Isotopes, Andover, Massachusetts. Poly(acrylic acid) (PAA, MW = 450.000), Polyethylenimine (PEI, MW = 10,000), Poly(methyacrylic acid, PMAA), Poly(methyacrylamide) PMA, water-soluble, hydrophilic, were purchased from Polysciences, Inc. Mercury (II) nitrate monohydrate, $15.5 \mathrm{~N}$ perchloric acid, potassium hydrogen phthalate, picolinic acid, $0.987 \mathrm{~N} \mathrm{NaOH}, 0.953 \mathrm{~N} \mathrm{HCl}, \mathrm{NaOH}$ pellets, 2propanol, Ethylenediamine, glycine and succinic acid were purchased from Aldrich Chemical Company.

\subsection{Sample Preparation:}


2.1.1 Preparation of 0.3 M Cd(ClO $\left.)_{4}\right)_{2}$ solution: This was done by dissolving 1.251g of $\mathrm{Cd}\left(\mathrm{ClO}_{4}\right)_{2} \cdot 6 \mathrm{H}_{2} \mathrm{O}$ in $10 \mathrm{ml}$ of $0.1 \mathrm{M}$ perchloric acid, to give $0.3 \mathrm{M} \mathrm{Cd}\left(\mathrm{ClO}_{4}\right)_{2}$ in $0.1 \mathrm{M}$ perchloric acid.

2.1.2 Preparation of $\mathbf{C d C l}_{2}$ solution: This was done by dissolving $65 \mathrm{mg}$ of $\mathrm{CdO}$ (12.86\% natural abundance) in $2 \mathrm{ml}$ of hot concentrated $\mathrm{HCl}$ acid. The aliquot was evaporated on a hot plate until it was dried out and the sediment turned to white powder. The sediment was then dissolved in $3.5 \mathrm{ml}$ of $\mathrm{D}_{2} \mathrm{O}$.

2.1.3 Cdmium-Polymer sample preparation: 60 to $62 \mathrm{mg}$ of polyethylene (PEIC or PEIP) was dissolved in $1 \mathrm{ml}$ of the $\mathrm{CdCl}_{2}$ solution, for the NMR measurements.

\subsection{Model Compound Studies}

This work is a two-phase project. The first is to measure the chemical shifts of CdPolymers (PEIC and PEIP). The second phase is measuring the chemical shifts of welldefined molecular analogs of expected binding sites (Model compounds/structures). Understanding the chemical shift anisotropy of $\mathrm{Cd}, \mathrm{Hg}$, $\mathrm{Ni}$ and other metals will provide information on the chemical environments of the metals. This is specifically important in chelating environments where the nature of the ligands can change. For example,

$-\mathrm{N} \quad$ can become protonated

$-\mathrm{N}$ substituents can vary

$>\mathrm{C}=\mathrm{O}$ becomes $>\mathrm{C}-\mathrm{O}^{-}$

Other complexing moieties may be present; e.g., we may have primary, secondary and even tertiary amines that can bind to metals, all to varying degrees. Other parameters that can and will affect observed resonance positions include, $\mathrm{pH}$, Osmotic strength, (ionic strength), competitive binding with other groups, other metals, temperature, etc. Some of the proposed model compounds and structures include:

1. Ethylenediamine (2 amines)

2. EDTA or PANAM -0.5 , containing 4 surface carboxylate groups

3. Bis-diethylenediamine, containing six surface carboxylate groups

4. Cyclam, containing 4 amine groups

5. Glycine, aminocarboxylate 
6. Glycolic, gluconic acids, hydroxycarboxylates

7. Succinic acid, dicarboxylate

8. Picolinic acid, carboxylate with neutral N group

9. Starburst dendrimer generation 1.5

10. Poly (acrylic acid) PAA

11. Poly (methylacrylic acid), PMAA

12. Polyacrylamide

\section{Results and Discussion}

Table 1and Figure 1 show the chemical shift values for the ${ }^{113} \mathrm{Cd}-\mathrm{PEIC}$ complexes. The peaks are broad at low percent functionalization. As the level of carboxyl-modification increases, the peaks become sharper, as can be seen for $75 \%$ and $100 \%$ functionalized PEIC. The apparent reason for this is related to the number of exposed binding sites for Cadmium. It seems that the binding site for PEIC is the carboxyl group, $\left(>\mathrm{C}-\mathrm{O}^{-}\right)$. At low percent functionalization, the number of binding sites is few. This leads to rapid exchange between free and bound $\mathrm{Cd}^{2+}$ ions. This results in the broadening of NMR peaks. As the polymers become more functionalized the rapid exchange reduces drastically, resulting in narrower peaks. ${ }^{113} \mathrm{Cd}^{2+}$ ion is an excellent metal ion probe due to its ability to form complexes with many different conformations and ligand numbers ${ }^{18}$. Furthermore, the ${ }^{113} \mathrm{Cd}^{2+}$ chemical shift covers a wide range from about 800 to $-200 \mathrm{ppm}$, and the nature of the coordinating ligands and their coordination numbers are strongly reflected in the chemical shift ${ }^{19-21} \cdot{ }^{113} \mathrm{Cd}$ chemical shift in solutions of cadmium-containing coordination compounds is reflective of the directly bonded heteroatom of the ligand. In particular, ligands that bind through oxygen cause increased shielding of the $\mathrm{Cd}$ nucleus, while ligands that bind through nitrogen produce deshielding of the $\mathrm{Cd}$ nucleus. Ligands that bind via sulfur produce very large deshielding (downfield chemical shifts). This might partially explain the chemical shifts of the different levels of functionalization. Since the binding sites of Cadmium to PEIC are through oxygen in the carboxyl moieties, explains while the $75 \%$ and $100 \%$ modified PEIC are upfield to the $25 \%$ and $50 \%$ PEIC. 
Table 2 and Figure 2 show the chemical shift values of ${ }^{113} \mathrm{Cd}$-PEIP complexes. As the $\%$ functionalization increases from $25 \%$ to $75 \%$, the chemical shift values go upfield, as a result of increased shielding by the phosphorus atom. Figure 3 and Table 3 show the binding characteristics of some model compounds. The binding of Cadmium to amine-containing molecules a downfield shift as shown by ${ }^{113} \mathrm{Cd}$-Ethylenediamine chemical shift at $351.106 \mathrm{ppm}$.. Ethylenediamine has two amine groups, leading to long downfield shift. Succinic acid has two carboxylic groups and therefore has an upfield shift at $45.41 \mathrm{pp}$.

The use of Model compounds to investigate metal-binding characteristics of polymers is a standard procedure in NMR spectroscopy. Recently, an investigation of Cd (II)-carboxylate systems (mono- and di-carboxylic acids) in aqueous solution was carried out by Chung and Moon ${ }^{22}$, using ${ }^{113} \mathrm{Cd}$ NMR spectroscopy. In this study, they found out that, in Cd(II)-carboxylate systems, an increase in the carboxylate-to-Cadmium ratio caused the chemical shift to move towards an upfield region: the cadmium ion becomes more shielded when coordinated water molecules are displaced by carboxylates. Figure 4 compares the structures of regular PEI, PEIC, and Starburst PANAM Dendrimer 1.5, and shows why a model structure like the dendrimer will be appropriate for the study of the structure and reactions of PEIC.

\section{CONCLUSIONS}

Polyethylenimine (PEI), a water-soluble polymerhas been found to have great affinity to binding with metals, due to its polyelectrolyte character and large macromolecular size. PEI binds readily with $\mathrm{Cd}$ (II), $\mathrm{Hg}$ (II), etc., and therefore very useful for sequestering metal ions from aqueous streams. . ${ }^{113} \mathrm{Cd}$ chemical shift in solutions of cadmium-containing coordination compounds is reflective of the directly bonded heteroatom of the ligand. In particular, ligands that bind through oxygen cause increased shielding of the $\mathrm{Cd}$ nucleus, while ligands that bind through nitrogen produce deshielding of the Cd nucleus. Ligands that bind via sulfur produce very large deshielding (downfield chemical shifts). 


\section{REFERENCES}

1. Boulanger, Y., Armitage, I. M., Miklossy, K. A., Winge, D. R., J. Biol. Chem. 257, 13717 (1982).

2. Bobsein, B. R., Myers, R. J., J. Am. Chem. Soc., 102, 2454 (1980).

3. Otoves, J. D., Armitage, I. M., Biochemistry, 19, 4031 (1980).

4. Evelhoch, J. L., Bocain, D. L., Sudmeier, Biochemistry, 20, 4951 (1981).

5. Ellis, P. D., Science, 221, 1141 (1983).

6. Summers, M. F., Coord. Chem. Rev. 86, 43 (1988).

7. Cardin A. D., Ellis, P. D., Odom, J. D., Howard, J. W., J. Am. Chem. Soc. 97, $1672(1975)$.

8. Haberkorn, A. R., Que, I., Gillum, W. O., Holm, R. H., Liu, C. S., Lord, R. C., Inorg. Chem. 15, 2408 (1976).

9. Jensen, C. F., Deshmukh, Jacobsen, H. J., Inners, R. R., Ellis, P. D. J. Am. Chem. Soc. 103, 3659 (1981).

10. Rodesiler, P. F., Amma, E. L., J. Chem. Soc. Chem. Commun. 182 (1982).

11. Freeland, Graeme N., Hoskinson, Ronald M., Mayfield, Robert J., Environ. Sci. Technol., 8(10), 942 (1974).

12. Friedman, M., Masari, M. S., J. Appl. Polymer Sci., 17, 2183 (1973).

13. Friedman, M., Waiss, A. C., Environ. Sci. Technol. 6, 457 (1972).

14. Friedman M., Harrison, C. S., Ward, H. W., Lundgren, H. P. J. Appl. Polymer Sci., 17, 377 (1973).

15. Takahashi, H., Hirayama, K., Nature, 232, 201(1971).

16. Roberts, E. J., Rowlands S. P., Textile Res. J., 41, 864 (1971).

17. Roberts, E. J., Rowlands S. P., Environ. Sci. Technol. 7, 552, (1973).

18. C. K. Larvine, A. Rogers, M. Morton, W. R. Carper, Environ. Sci. Technol., 30, 2828-2831, 1996

19. M. F. Summers, Coord. Chem. Rev., 86, 43-134, 1988

20. C. Johansson, T. Drakenberg, Annu Rev. NMR Spectrosc., 22, 1-59, 1989.

21. K. H. Chung, S. W. Rhee, H. S. Shin, C. H. Moon, Can. J. Chem., 74, 1360-1365, 1996.

22. K. H. Chung, C. H. Moon, J. Chem. Soc. Dalton Trans. 75, 1996. 